\title{
Pecularities and applications of aryl-alcohol oxidases from fungi
}

\author{
Vlada B. Urlacher ${ }^{1} \cdot$ Katja Koschorreck $^{1}$ \\ Received: 5 March 2021 / Revised: 3 May 2021 / Accepted: 6 May 2021 / Published online: 17 May 2021 \\ (C) The Author(s) 2021
}

\begin{abstract}
Aryl-alcohol oxidases (AAOs) are FAD-containing enzymes that oxidize a broad range of aromatic as well as aliphatic allylic alcohols to aldehydes. Their broad substrate spectrum accompanied by the only need for molecular oxygen as cosubstrate and production of hydrogen peroxide as sole by-product makes these enzymes very promising biocatalysts. AAOs were used in the synthesis of flavors, fragrances, and other high-value-added compounds and building blocks as well as in dye decolorization and pulp biobleaching. Furthermore, AAOs offer a huge potential as efficient suppliers of hydrogen peroxide for peroxidase- and peroxygenase-catalyzed reactions. A prerequisite for application as biocatalysts at larger scale is the production of AAOs in sufficient amounts. Heterologous expression of these predominantly fungal enzymes is, however, quite challenging. This review summarizes different approaches aiming at enhancing heterologous expression of AAOs and gives an update on substrates accepted by these promising enzymes as well as potential fields of their application.
\end{abstract}

\section{Key points}

- Aryl-alcohol oxidases (AAOs) supply ligninolytic peroxidases with $\mathrm{H}_{2} \mathrm{O}_{2}$.

- AAOs accept a broad spectrum of aromatic and aliphatic allylic alcohols.

- AAOs are potential biocatalysts for the production of high-value-added bio-based chemicals.

Keywords Aryl-alcohol oxidase · GMC family · Lignin degradation · Aryl alcohols · Aliphatic allylic alcohols · Biocatalysis · Bio-based precursors $\cdot$ Flavors

\section{Introduction}

Since decades, oxidoreductases have been recognized as valuable tools for synthetic chemistry, because they catalyze reactions that are often difficult or impossible to achieve with classical chemical catalysts (Hall 2020). Oxidases, reductases, oxygenases, and dehydrogenases that enable selective synthesis of chiral alcohols, ketones, aldehydes, and carbon acids have been successfully integrated into biocatalytic and chemoenzymatic processes. Oxidoreductases are of vital interest also for developing the bioeconomy via efficient conversion of renewable feedstocks like lignocellulose to fuels and high-valueadded chemicals. White-rot fungi secrete a bunch of oxidative enzymes participating in the degradation of lignocellulosic biomass as a central step in carbon recycling. Peroxidases

Katja Koschorreck

Katja.Koschorreck@hhu.de

1 Institute of Biochemistry, Heinrich-Heine-University Düsseldorf, Universitätsstraße 1, 40225 Düsseldorf, Germany responsible for lignin degradation require sources of $\mathrm{H}_{2} \mathrm{O}_{2}$ (Hammel 1997). Thus, fungi produce oxidases such as arylalcohol oxidases that generate $\mathrm{H}_{2} \mathrm{O}_{2}$ required by the peroxidases (Fig. 1). Aryl-alcohol oxidases (AAOs, EC 1.1.3.7), also known as veratryl-alcohol oxidases, aromatic alcohol oxidases, or benzyl-alcohol oxidases, are flavin-adenine-dinucleotide (FAD)-containing enzymes that catalyze the oxidation of aromatic and aliphatic allylic primary alcohols to the corresponding aldehydes while reducing molecular oxygen to $\mathrm{H}_{2} \mathrm{O}_{2}$ (Guillen et al. 1992). Some other flavin-containing oxidases like vanillyl alcohol oxidase (EC 1.1.3.38) or 4hydroxymandelate oxidase (decarboxylating; EC 1.1.3.19) that can also oxidize aromatic or phenolic compounds (Bhat and Vaidyanathan 1976; de Jong et al. 1992b; Ewing et al. 2020; Martin et al. 2020) will not be considered herein.

Within this review, we will focus on AAOs from fungi. Since their discovery in 1960, significant knowledge has been gained with regard to structural, spectral, biochemical, and catalytic properties of fungal AAOs. All these achievements are a subject of several excellent reviews (Hernandez-Ortega et al. 2012a; Serrano et al. 2020) and therefore will only be 


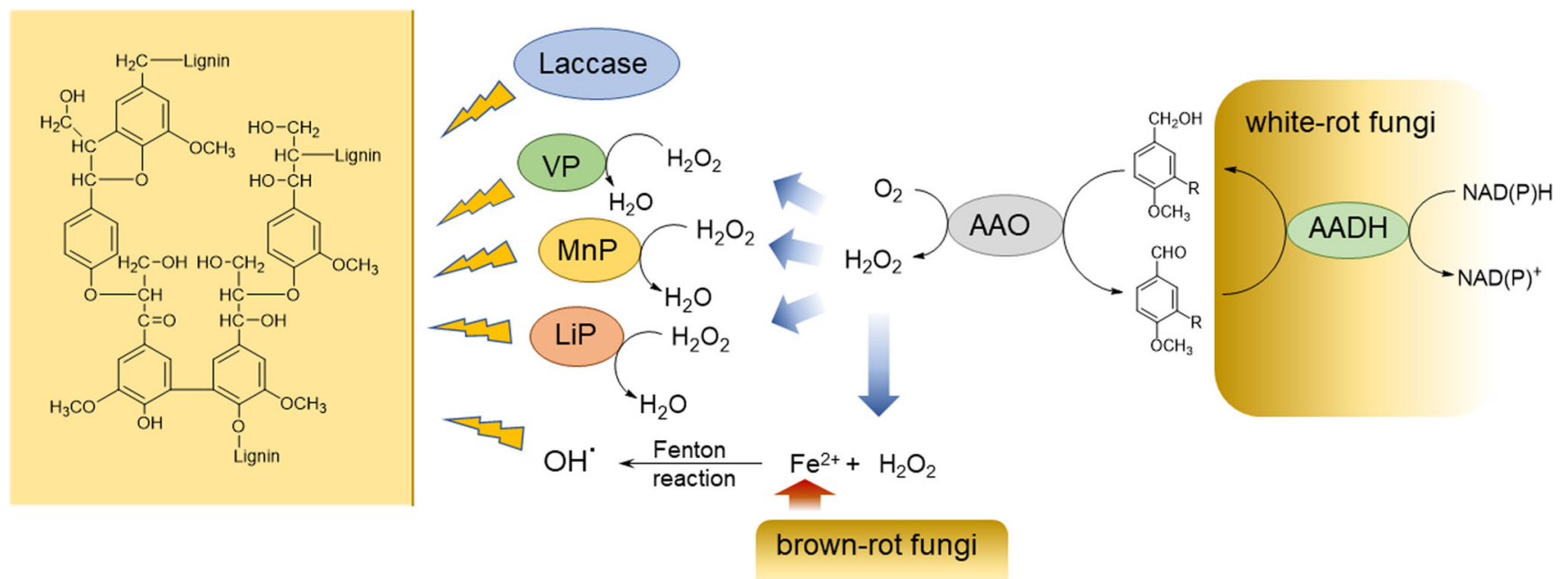

Fig. 1 Involvement of AAO in lignin degradation. $V P$ versatile peroxidase, $M n P$ manganese peroxidase, $L i P$ lignin peroxidase, $A A D H$ aryl-alcohol dehydrogenase

touched briefly here. Like all oxidases, AAOs are independent of the costly nicotinamide cofactors required by oxygenases, and rely only on molecular oxygen as final electron acceptor. These features combined with the broad substrate spectrum and quite high stability make these enzymes potential biocatalysts for the production of bio-based precursors for plastics, bioactive compounds, and fragrances. Indeed, a number of publications, particularly those which have appeared in the last years, are dedicated to the use of AAOs in biocatalysis. Recently, progress was also made in protein engineering of AAOs for improved expression, enhanced activity, and increased selectivity. Broader exploitation and protein engineering of AAOs are however challenged by their difficult accessibility due to low concentrations in original fungi and insufficient expression in recombinant microorganisms. Whereas we will not specifically focus on the methods of enzyme engineering of AAOs described in a recent review (VinaGonzalez and Alcalde 2020), we will include a number of examples focusing on synthetic and biotechnological applications of wild-type AAOs and engineered variants thereof, and discuss various heterologous hosts and strategies aiming to enhance heterologous expression of these enzymes.

\section{Occurrence and GMC superfamily}

Since the first report in 1960 by Farmer et al. (1960), who identified aromatic alcohol oxidase activity in the growth medium of the basidiomycete Polystictus (Trametes) versicolor, AAO activity has been found in cultures of many other basidiomycetes like Pleurotus species (Bourbonnais and Paice 1988; Galperin et al. 2016; Guillen et al. 1990; Sannia et al. 1991; Varela et al. 2000), Bjerkandera adusta (Muheim et al. 1990b; Romero et al. 2009), Bjerkandera sp. BOS55 (de Jong et al. 1992a), Coprinopsis cinerea (Tamaru et al. 2018),
Phanerochaete chrysosporium (Asada et al. 1995), Ustilago maydis (Couturier et al. 2016), and ascomycetous fungi such as Aspergillus terreus (Chakraborty et al. 2014), Botrytis cinerea (Goetghebeur et al. 1992), Fusarium proliferatum (Regalado et al. 1999), Geotrichum candidum (Kim et al. 2001), and Thermothelomyces thermophilus (Kadowaki et al. 2020). Although predominantly found in fungi, enzymes with AAO activities have also been reported in bacteria Sphingobacterium sp. (Tamboli et al. 2011), Streptomyces sp. (Riyadi et al. 2020), and Methylovorus sp. (Dijkman and Fraaije 2014), in the phytopathogenic insects Chrysomela populi and Phratora vitellinae (Brückmann et al. 2002), and in gastropods such as Arion ater, Helix aspersa, and Limax flavus (Large and Connock 1993; Mann et al. 1989).

According to their sequence and structure similarity, most flavin-containing oxidases have been classified in six families (Dijkman et al. 2013; Martin et al. 2020). AAOs belong to one of these families, the glucose-methanol-choline (GMC) oxidoreductase family, defined by Cavener in 1992 (Cavener 1992). GMC oxidoreductases were identified in ascomycetous and basidiomycetous fungi, plants, insects, and bacteria (Cavener 1992; Iida et al. 2007; Martin et al. 2020). Recently, hydroxymethylfurfural oxidases (HMFOs; EC 1.1.3.47) have been discovered which also belong to the GMC oxidoreductase family and oxidize aromatic primary alcohols, aldehydes, and thiols (Dijkman and Fraaije 2014; Ewing et al. 2014; Vinambres et al. 2020). While AAOs are secreted by fungi, HMFOs have been found in bacteria like Methylovorus sp. strain MP688 and Pseudomonas nitroreducens. HMFO from Methylovorus sp. strain MP688 is, for example, an intracellular bacterial enzyme with low sequence identity to AAOs (Dijkman and Fraaije 2014).

In 2013, the GMC oxidoreductases were assigned to the "Auxiliary Activities 3" (AA3) family in the CarbohydrateActive enZyme (CAZy) database (Levasseur et al. 2013). The 
"auxiliary" enzymes help the carbohydrate-active enzymes like glycoside hydrolases, polysaccharide lyases, and carbohydrate esterases to gain a better access to carbohydrates in plant cell wall. Four subfamilies belong to the AA3 family: AA3_1 includes for the most part cellobiose dehydrogenases (CDHs, EC 1.1.99.18); AAOs together with glucose 1oxidases (GOx, EC 1.1.3.4), glucose-1-dehydrogenases (GDHs, EC 1.1.5.9), and pyranose dehydrogenases (PDHs, EC 1.1.99.29) belong to the subfamily AA3_2; AA3_3 contains alcohol oxidases (AOx, EC 1.1.3.13); and AA3_4 comprises pyranose 2-oxidase (POx, EC 1.1.3.10).

The spectrum of substrates accepted by GMC oxidoreductases covers a broad range of sugars and alcohols. Depending on the type of the final electron acceptor, the GMC family members can be divided into two groups: oxidases, that transfer electrons to molecular oxygen, and dehydrogenases that transfer electrons to quinones, phenoxy radicals, or metal ions and show no or negligible oxygen reactivity. Fungal arylalcohol:quinone oxidoreductases (AAQOs) possess a similar substrate spectrum as AAOs but utilize quinones as final electron acceptor rather than molecular oxygen (Mathieu et al. 2016). Based on sequence similarities of $\sim 10,000$ putative fungal GMC oxidoreductases, these enzymes were classified in five clusters: AOx, CDH, POx, GOx-GDH, and AAOPDH (Sützl et al. 2019). Phylogenetic and sequence studies of the individual clusters shed light into the sequencestructure-function relationship of the GMC family (Sützl et al. 2019). According to this analysis, the AAO-PDH cluster showed a split into three clades: AAO, AAO-like, and PDH. AAOs and AAQOs did not appear in separate clades, indicating that only minor amino acid changes determine the specificity for the final electron acceptor.

\section{Functions in nature}

As mentioned above, in nature, AAOs are involved in degradation of lignocellulosic biomass. Lignocellulose is the most abundant renewable feedstock that provides a rich source for biofuels and value-added chemicals. Thus, effective bioconversion of lignocellulosic biomass has attracted significant attention from both academic and industrial points of view (Becker and Wittmann 2019). The most recalcitrant component of lignocellulose is lignin that can be decomposed by fungi and some bacterial species (Bugg et al. 2011; de Gonzalo et al. 2016). Wood-decaying white-rot fungi degrade lignin by using a large set of enzymes including ligninmodifying oxidative enzymes and "auxiliary" enzymes that do not degrade lignin on their own but assist other enzymes during lignin decomposition. Fungal oxidative enzymes involved in lignin degradation are laccases and the class II peroxidases lignin peroxidase (LiP), manganese peroxidase (MnP), and versatile peroxidase (VP) (Fig. 1). "Auxiliary" enzymes involved in lignin degradation include $\mathrm{H}_{2} \mathrm{O}_{2}$-generating AAO, glyoxal oxidase (GLOX, EC 1.2.3.5), and pyranose 2-oxidase but also $\mathrm{CDH}, \mathrm{GDH}$, and others. The well-studied lignin-degrading white-rot fungus Pycnoporus cinnabarinus contains, for example, 9 class II peroxidase encoding sequences, 5 putative laccase genes, 7 putative glyoxal oxidase genes, and 3 AAO encoding sequences (Levasseur et al. 2013). In comparison, brown-rot fungi lack class II peroxidases and instead produce enzymes that are involved in extracellular formation of Fenton's reagent (Levasseur et al. 2014) (Fig. 1). $\mathrm{Fe}$ (II) reduces $\mathrm{H}_{2} \mathrm{O}_{2}$ to hydroxyl free radicals which cause cellulose degradation and methanol release from lignin by demethylation (Martinez et al. 2011). Methanol is used by methanol oxidase (MOX) to produce $\mathrm{H}_{2} \mathrm{O}_{2}$. MOX is the most abundant GMC oxidoreductase and the main oxidase involved in wood decay by brown-rot fungi (Daniel et al. 2007; Ferreira et al. 2015a). Thus, white-rot fungi rely on $\mathrm{H}_{2} \mathrm{O}_{2}$-producing enzymes like AAOs for ligninolytic peroxidases while in brown-rot fungi $\mathrm{H}_{2} \mathrm{O}_{2}$ released by MOX is utilized for Fenton's reagent formation. This is in agreement with the higher number of AAOs found in peroxidase-producing white-rot fungi compared to brown-rot fungi (Ferreira et al. 2015a; Levasseur et al. 2013). Furthermore, extracellular production of AAO along with LiP by the white-rot fungus B. adusta (Muheim et al. 1990a) and AAO together with LiP and MnP by the white-rot fungi P. ostreatus and T. pubescens (Casieri et al. 2008) supports the hypothesis that AAOs are involved in lignin decomposition. Notably, the thermophilic cellulolytic ascomycete Thermothelomyces thermophilus M77 produces AAO but no lignin or manganese peroxidase (Berka et al. 2011), which suggests that AAO might be also involved in Fenton's reagent formation.

To supply class II peroxidases with $\mathrm{H}_{2} \mathrm{O}_{2}$ for breakdown of lignin, wood-decaying fungi produce small aromatic aldehydes like anisaldehyde or veratraldehyde that are reduced by NADPH-dependent aryl-alcohol dehydrogenases to the corresponding alcohols which are accepted by AAOs as substrates (Guillen and Evans 1994). AAOs complete the redox cycle by transferring the electrons from aryl alcohols to molecular oxygen thus producing $\mathrm{H}_{2} \mathrm{O}_{2}$ and aldehydes. Lignin-derived aryl alcohols and aldehydes may also be used as substrates by AAOs for $\mathrm{H}_{2} \mathrm{O}_{2}$ production. Besides oxidizing benzylic alcohols produced by fungi or released in course of lignin decomposition, AAOs accept a broad range of other substrates, which are described in more detail in the following.

\section{Structure and mechanism}

Members of the GMC family contain FAD as cofactor and share a similar topologic fold: They are composed of a highly conserved $\mathrm{N}$-terminal domain involved in FAD binding, and a 
less conserved C-terminal domain involved in substrate binding (Martin et al. 2020). The N-terminal domain has the Rossmann super-secondary structure with an ADP-binding $\beta \alpha \beta$ fold. The variability of the $\mathrm{C}$-terminal domain reflects the diversity of substrates accepted by the members of this family (Sützl et al. 2018). Common to all GMC members is the presence of a highly conserved catalytic histidine residue involved in substrate oxidation and FAD reoxidation (Martin et al. 2020).

For many years, only the crystal structure of $P e A A O$ from $P$. eryngii with and without inhibitor was available (Carro et al. 2017; Fernandez et al. 2009). The enzyme was produced as selenomethionine derivative in $E$. coli and refolded in vitro. Structure analysis revealed that this AAO is a monomer that is, similar to other GMC oxidoreductases, composed of two domains, an FAD-binding domain and a substrate-binding domain. Non-covalently bound FAD cofactor is stabilized by $\mathrm{H}$ bonds formed by the residues of the conserved $\beta \alpha \beta$ fold in the N-terminal domain. In this enzyme, the isoalloxazine ring of FAD is buried inside the protein. The substrate-binding domain is formed by a six-stranded antiparallel $\beta$-sheet flanked by two long $\alpha$-helices. Whereas one of the best studied enzymes from the GMC family, glucose oxidase, has an open wide active site, the accessibility to the active site of PeAAO is restricted by an additional loop that forms a funnel-like hydrophobic channel. This channel connects the solvent with the FAD cofactor through a bottleneck formed by three aromatic residues, Tyr92, Phe397, and Phe501, which limit substrate diffusion to the active site. The active site is located in front of the re-side of the isoalloxazine ring of FAD and near two histidines, His502 and His546, postulated as catalytic residues (Ferreira et al. 2006) (Fig. 2).
Sequence comparison of the AAO-PDH clade members of the GMC family revealed that Tyr92 and Phe501 located in the hydrophobic substrate access channel of PeAAO are conserved among many AAOs, but absent in the PDH clade (Sützl et al. 2019). The loss of the narrow hydrophobic channel was suggested as the starting point for widening the substrate entrance site to accept other substrates like sugars by $\mathrm{PDH}$. Another feature to discern AAO and PDH is the covalently bound FAD in PDH. The covalently bound FAD cofactor is usually related to higher redox potentials (Heuts et al. 2009) probably resulting in an altered substrate spectrum and thus contributing to the differentiation of PDHs and AAOs.

In 2020, the crystal structure of MtAAOx from T. thermophilus (formerly Myceliophthora thermophila) was solved and compared with the structure of PeAAO (Kadowaki et al. 2020). MtAAOx was expressed and secreted by A. nidulans and crystallized in glycosylated form. Comparative analysis of the two structures has revealed that whereas the FAD-binding domain is strongly conserved in $M t \mathrm{AAOx}$ and $P e \mathrm{AAO}$, the substrate-binding domain and the substrate channel to the active site differ. MtAAOx possesses a wider substrate access channel connecting the active site with the solvent. The conserved catalytic histidines His579 and His622 are located in the easily accessible hydrophobic active site. Remarkably, three aromatic residues in the hydrophobic bottleneck present in PeAAO, Tyr92, Phe397, and Phe501, are not conserved in the MtAAOx structure. Furthermore, the MtAAOx structure has a unique $\mathrm{Ca}^{2+}$ binding pocket located near the catalytic site entrance. This element was not reported previously for any AA $3 \_2$ enzyme, and seems to stabilize the structure of the thermostable MtAAOx (Kadowaki et al. 2020).
Fig. 2 Catalytic site of PeAAO. View of the active site of $P e A A O$ (PDB entry 3FIM) with FAD depicted in yellow, catalytic His502 and His546 depicted in gray, and Tyr92 (green) and Phe501 (blue) located in the hydrophobic substrate access channel

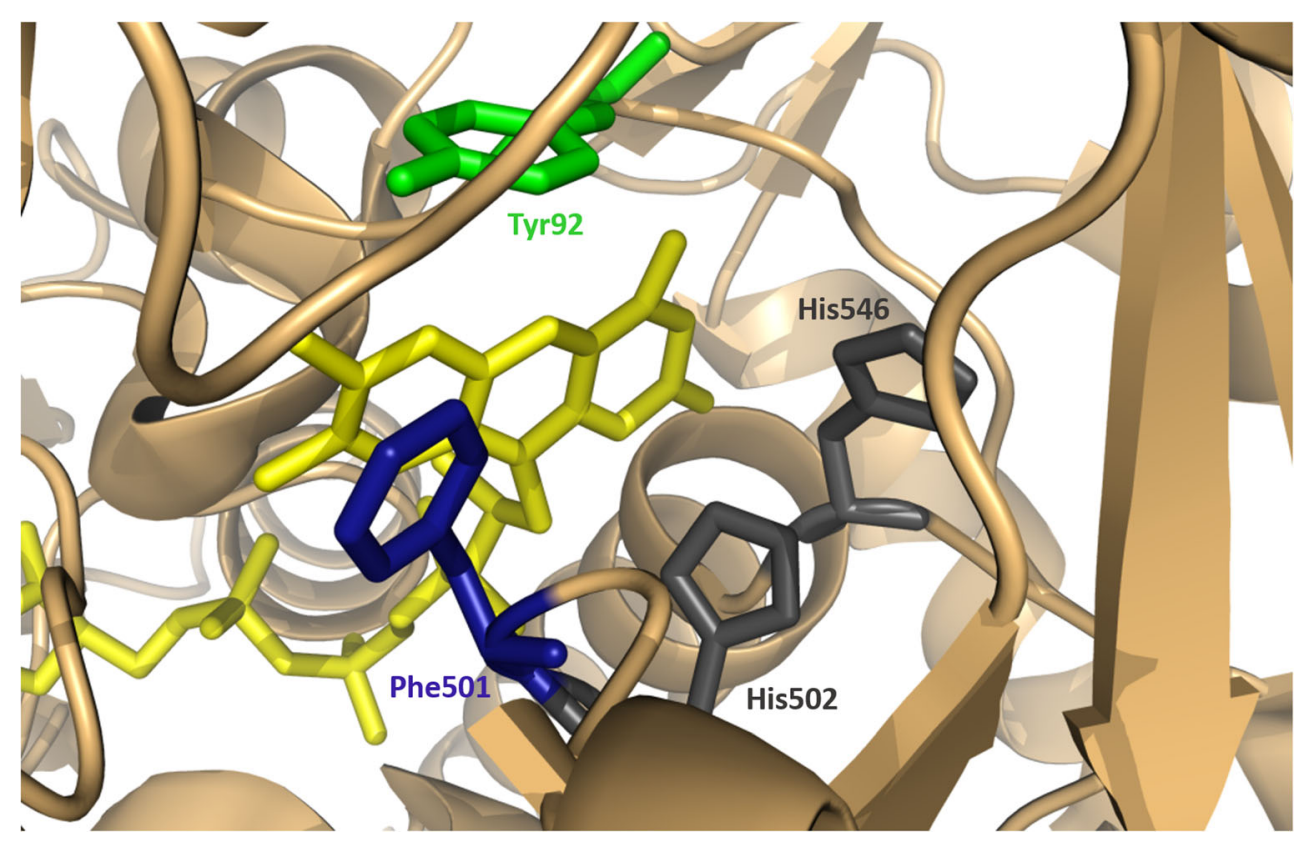


Like other GMC enzymes, the catalytic cycle of AAOs can be divided into two half-reactions, reductive and oxidative. In the reductive half-reaction, the alcohol substrate is oxidized via twoelectron abstraction and the reduced form of the flavin cofactor is formed; in the oxidative half-reaction, reduced FAD is reoxidized whereas molecular oxygen is reduced to hydrogen peroxide. Crystal structures, kinetic and spectroscopic analyses, QM/MM studies, docking experiments, and site-directed mutagenesis performed by A. T. Martinez and colleagues have provided a detailed picture of substrate access in the active site and catalytic mechanism of PeAAO which are summarized in the recent review (Serrano et al. 2020). The alcohol substrate interacts with Phe397 in the funnel-like hydrophobic channel, which induces a rearrangement of the loop that limits the access to the active site (Carro et al. 2018a). This rearrangement promotes the substrate in a catalytically relevant position in the active site, where it is stabilized through an aromatic stacking interaction with Tyr92 (Ferreira et al. 2015b). Docking of $p$-methoxybenzyl alcohol and QM/MM calculations demonstrated that the pro- $R$ hydrogen of the substrate is located 2.4 A away from the N5 position of the isoalloxazine ring of the cofactor, enabling hydride transfer and yielding the reduced $\mathrm{FAD}$ during the reductive half-reaction. In the same time, the hydroxyl proton of the substrate is abstracted by the catalytic base His502, assisted by His 546 , which forms an $\mathrm{H}$ bond with the alcohol (Hernandez-Ortega et al. 2012c). Although proton abstraction and hydride transfer are highly coupled, they occur through non-synchronous concerted mechanism. Unlike other GMC oxidoreductases, no stable alkoxide intermediate was detected, which suggests that AAO follows a different mechanism for alcohol oxidation (Hernandez-Ortega et al. 2011a).

Molecular oxygen accesses the buried FAD by diffusion through the narrow hydrophobic channel, where Phe501 was proposed to assist the $\mathrm{O}_{2}$ molecule to approach the flavin $\mathrm{C} 4 \mathrm{a}$ position (Hernandez-Ortega et al. 2011b). The structure of MtAAOx from T. thermophilus reveals a wider channel, which might explain the 202-times lower $\mathrm{O}_{2}$ reactivity of this oxidase than PeAAO. Interestingly, the replacement of Phe501 through alanine in PeAAO resulted in reduction of $\mathrm{O}_{2}$ reactivity (Hernandez-Ortega et al. 2011b).

In the oxidative half-reaction in PeAAO, reduced FAD first reacts with molecular oxygen to form a superoxide anion radical and neutral flavin semiquinone. Subsequently, one hydride (originally abstracted from the alcohol substrate in the reductive half-reaction) from the flavin N5 and one proton originating either from the catalytic His502 or from the solvent are transferred to the superoxide anion to furnish $\mathrm{H}_{2} \mathrm{O}_{2}$ (Carro et al. 2018c). The question, whether the first electron transfer is coupled to the proton transfer remains open. Differently from flavin monooxygenases (Paul et al. 2021; Toplak et al. 2021) and some flavin oxidases (Sucharitakul et al. 2008; Wongnate and Chaiyen 2013), a C4a-hydroperoxyflavin is not stabilized in PeAAO (Serrano et al. 2020).

\section{Substrate spectrum}

Originally declared as aryl-alcohol oxidases, the enzymes belonging to this group accept a quite broad range of substrates (Fig. 3). However, substrate preferences differ for different AAOs. Activity of AAOs from Pleurotus strains was found to depend on the position and properties of aromatic ring substituting groups (Guillen et al. 1992; Jankowski et al. 2020). Whereas an electron-withdrawing substituent like nitro group at the para-position of the aromatic ring had a negative effect on enzyme activity (Guillen et al. 1992), an electrondonating substituent like methoxy-group at this position enhanced enzyme activity compared to unsubstituted benzyl alcohol (Galperin et al. 2016; Guillen et al. 1992; Jankowski et al. 2020; Varela et al. 2000). Other AAOs like rCcAAO from $C$. cinerea, BAO from B. cinerea, and AOx from A. terreus oxidized benzylic alcohols with a methoxysubstitution at the para- or meta-position of the aromatic ring equally well (Fig. 4A). Interestingly, the presence of parahydroxy group differently affected the activity of AAOs: In comparison with benzyl alcohol, $p$-hydroxybenzyl alcohol was oxidized with a negligible activity by PeAAO (Guillen et al. 1992), but faster by $C$. cinerea $\mathrm{r} C \mathrm{AAO}$ (Tamaru et al. 2018). Whereas vanillyl alcohol was barely oxidized by PeAAO2 from $P$. eryngii P34, isovanillyl alcohol was oxidized by the same enzyme with an almost 3-times higher activity than benzyl alcohol (Jankowski et al. 2020) (Fig. 4B). Differently, C. cinerea $\mathrm{rCc}$ AAO catalyzed oxidation of both vanillyl alcohol and isovanillyl alcohol with similar activities, which were only slightly lower than activity towards benzyl alcohol (Chakraborty et al. 2014; Tamaru et al. 2018). AAO of Bjerkandera BOS55 prefers mono- and dichlorinated anisyl alcohols as substrates (de Jong et al. 1994). Polyunsaturated aliphatic alcohols like trans,trans-2,4hexadien-1-ol or 2,4-heptadien-1-ol were recognized as favorable substrates of many AAOs (Guillen et al. 1992; Jankowski et al. 2020; Tamaru et al. 2018). Non-conjugated aliphatic allylic alcohols like trans-2-hexen-1-ol, trans-2-hepten-1-ol, trans-2-octen-1-ol, and trans-2-cis-6-nonadien-1-ol were oxidized by $P e \mathrm{AAO} 2$ from $P$. eryngii $\mathrm{P} 34$ to a much lesser extent (Jankowski et al. 2020). Of the aromatic alcohols, 2naphthalenemethanol was identified as most easily oxidized by Pleurotus AAOs followed by 1-pyrenemethanol (Guillen et al. 1992; Jankowski et al. 2020). 9-Anthracenemethanol was not accepted as substrate at all, probably due to steric constraints. Recently, piperonyl alcohol, cumic alcohol, and 2-thiophenemethanol were identified as AAO substrates as well (Jankowski et al. 2020). These results indicate that the substrate scope of AAOs is dependent on the chemical properties and reactivity of the substrate and is controlled by the size and properties of the active sites. Obviously, a comparative structure-function analysis including more structural information from various AAOs will enable the identification of 
Fig. 3 Substrates accepted by AAOs. Alcohols are depicted in blue, aldehydes in red

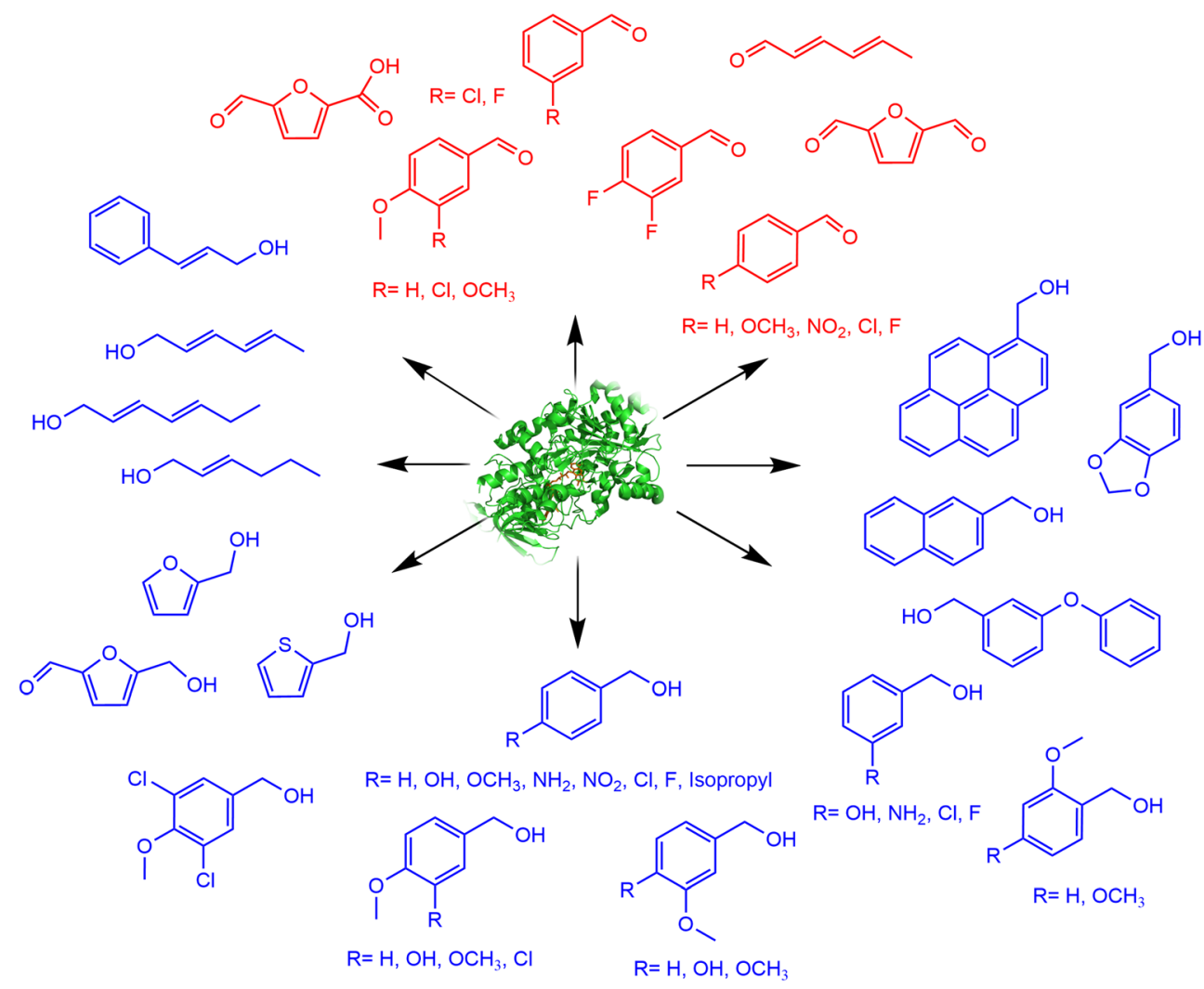

positions or regions in the active sites responsible for different substrate preferences and provide a basis for rational or semirational protein engineering of different AAOs.

In rare cases, AAOs catalyze the oxidation of aldehyde substrates to the corresponding acids. Aldehyde oxidation catalyzed by AAOs was proposed to mainly proceed via the gemdiols formed by aldehyde hydration, and thus following the mechanism analogous to alcohol oxidation (Ferreira et al. 2010). Cleavage of one of the gem-diol O-H bonds involves the catalytic His502 as a base, and the presence of electronwithdrawing or electron-donating ring substituting groups

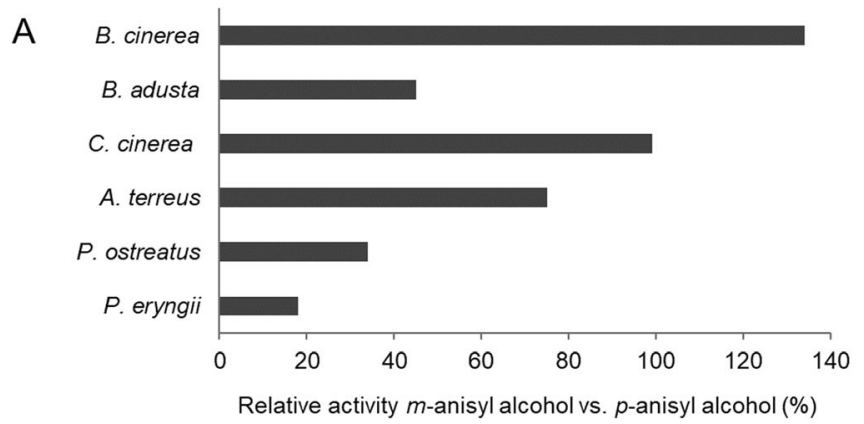

Fig. 4 Substrate specificity of AAOs towards $m$-and $p$-anisyl alcohol (A) and vanillyl and isovanillyl alcohol (B). A Relative activity of AAOs from B. cinerea (Goetghebeur et al. 1992), B. adusta (Romero et al. 2009), C. cinerea (Tamaru et al. 2018), A. terreus (Chakraborty et al. 2014), P. ostreatus (Sannia et al. 1991), and P. eryngii (Guillen et al. 1992) towards $m$-anisyl alcohol. Activity towards $p$-anisyl alcohol was seems to stabilize or destabilize the gem-diol intermediate. In contrast to the substituted aromatic alcohols, PeAAO demonstrated the highest activity towards the aromatic aldehydes with electron-withdrawing substituents like nitro groups or chlorine at the para- or the ortho-positions. Although benzaldehyde was accepted as substrate, the highest activity of PeAAO was observed with $p$-chlorobenzaldehyde and $p$ nitrobenzaldehyde. The presence of an electron-donating methoxy-group at the para-position resulted in low or no activity like with veratraldehyde and $p$-anisaldehyde (Ferreira et al. 2010).

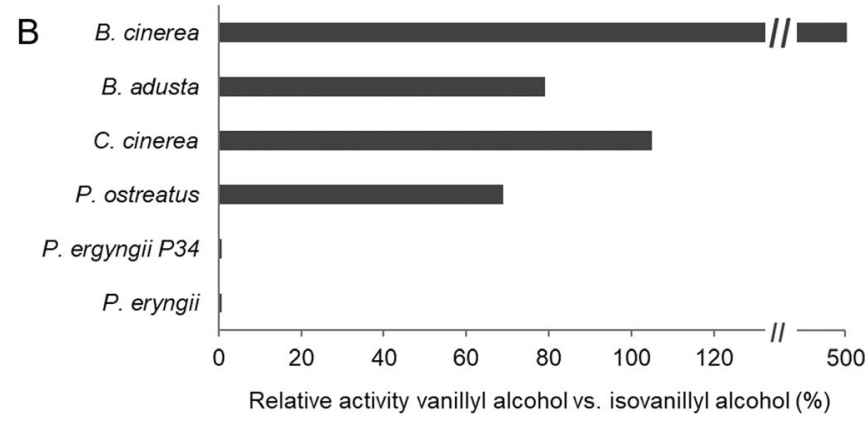

set to $100 \%$. B Relative activity of AAOs from B. cinerea (Goetghebeur et al. 1992), B. adusta (Romero et al. 2009), C. cinerea (Tamaru et al. 2018), P. ostreatus (Sannia et al. 1991), P. eryngii P34 (Jankowski et al. 2020), and P. eryngii (Guillen et al. 1992) towards vanillyl alcohol. Activity towards isovanillyl alcohol was set to $100 \%$ 


\section{Heterologous expression}

Although identified almost 60 years ago and widespread in nature, only a limited number of AAOs have been characterized so far. Since production levels of AAOs in their original host organisms are usually low and their purification from protein mixtures is tedious, overexpression of AAOs in heterologous microorganisms appears attractive to obtain sufficient amounts of enzymes for purification and biochemical characterization. Significant efforts have been undertaken to achieve high-level expression of AAOs in several microbial hosts, including Escherichia coli, Aspergillus nidulans, Pichia pastoris, Saccharomyces cerevisiae, and C. cinerea (Table 1). However, their heterologous expression seems to be quite challenging and often suffers from low yields. The first heterologous expression of an AAO was reported in 2001 by Varela and colleagues (Varela et al. 2001). They produced $P e \mathrm{AAO}$ in A. nidulans using an alcohol dehydrogenase promoter of $A$. nidulans (alcA) with a maximal volumetric activity of $400-500 \mathrm{mU} / \mathrm{mL}$ culture. A two-step chromatographic purification procedure yielded $3 \mathrm{mg}$ of active enzyme from 1 $\mathrm{L}$ of $A$. nidulans culture (Ferreira et al. 2005). Expression of the $P e A A O$ gene without its signal peptide sequence in $E$. coli under the control of the tac-promoter resulted in formation of inclusion bodies. After in vitro refolding and purification, $45 \mathrm{mg}$ of active AAO per liter of $E$. coli culture was obtained (Ruiz-Duenas et al. 2006). However, non-glycosylated $P e A A O$ expressed in E. coli showed lower $\mathrm{pH}$ and temperature stability compared to the glycosylated enzyme isolated from $P$. eryngii or expressed in A. nidulans (Ruiz-Duenas et al. 2006). To further improve AAO production level and to establish an appropriate expression host suitable for directed evolution, $S$. cerevisiae was investigated as host for the expression of PeAAO (Vina-Gonzalez et al. 2015). First, different secretion signal peptides of $S$. cerevisiae were investigated to promote secretion of PeAAO. The native secretion signal sequence of $P e A A O$ was replaced by either the preproleader sequence from the mating $\alpha$-factor (prepro $\alpha$ ) or the prepro-leader sequence from the $\mathrm{K}_{1}$ killer toxin (preproK) or chimeras of both, respectively. The prepro $\alpha-\mathrm{AAO}$ variant was produced at the highest yield of $1.5 \mathrm{U} / \mathrm{L}$ followed by the construct with a chimeric leader sequence pre $\alpha$ proK-AAO secreted at $0.5 \mathrm{U} / \mathrm{L}$. This difference might be explained by differences in efficiencies of cleavage of the signal peptide sequences. The prepro $\alpha$ sequence contains both the KEX2 and STE13 cleavage sites, while the preproK sequence carries only the KEX2 cleavage site. When high amounts of a heterologous protein bearing the $\alpha$-factor prepro-leader sequence are expressed in S. cerevisiae, the amount of STE13 protease in the Golgi might be not enough for efficient cleavage (Ahmad et al. 2014). Since the proK peptide was efficiently cleaved off by KEX2 protease, the pre $\alpha$ proK-AAO variant was used to further improve the $P e A A O$ secretion and activity by directed evolution. Several PeAAO mutant libraries were constructed by conventional directed evolution and using the method named Mutagenic Organized Recombination Process by Homologous In Vivo Grouping (MORPHING) in S. cerevisiae (Vina-Gonzalez et al. 2015). Out of 5000 clones screened, the FX7 variant with the mutation H91N demonstrated a 96-fold improved total activity compared to the

Table 1 Heterologous expression of AAOs in different hosts

\begin{tabular}{llllll}
\hline Name & Origin & Expression host & Vol. Activity (U/L) & Yield (mg/L) & Reference \\
\hline PeAAO & Pleurotus eryngii & Aspergillus nidulans & - & $3^{\text {a }}$ & Ferreira et al. (2005) \\
PeAAO & Pleurotus eryngii & Aspergillus nidulans & $400-500$ & - & Varela et al. (2001) \\
PeAAO & Pleurotus eryngii & Escherichia coli & - & $45^{\text {b }}$ & Ruiz-Duenas et al. (2006) \\
PeAAO_FX7 & Pleurotus eryngii & Saccharomyces cerevisiae & 48 & 2 & Vina-Gonzalez et al. (2015) \\
PeAAO_FX9 & Pleurotus eryngii & Saccharomyces cerevisiae & - & 4.5 & Vina-Gonzalez et al. (2018) \\
PeAAO_FX9 & Pleurotus eryngii & Pichia pastoris & 1378 & 25.5 & Vina-Gonzalez et al. (2018) \\
PeAAO2 & Pleurotus eryngii P34 & Pichia pastoris & 7250 & 315 & Jankowski et al. (2020) \\
AAO & Pleurotus sapidus & Coprinopsis cinerea & 125 & - & Galperin et al. (2016) \\
rAOx & Aspergillus terreus MTCC6324 & Escherichia coli & - & - & Chakraborty et al. (2014) \\
rCcAAO & Coprinopsis cinerea & Pichia pastoris & - & - & Tamaru et al. (2018) \\
MtAAOx & Thermothelomyces thermophilus M77 & Aspergillus nidulans & - & 8.4 & Kadowaki et al. (2020) \\
AAO & Thermothelomyces thermophilus & Aspergillus nidulans & $1906^{\mathrm{c}}$ & - & Liu and Wilkins (2020) \\
UmAAO & Ustilago maydis & Pichia pastoris & - & 1000 & Couturier et al. (2016) \\
\hline
\end{tabular}

${ }^{\text {a }}$ Purified enzyme

${ }^{\mathrm{b}}$ Purified and refolded from inclusion bodies

${ }^{\mathrm{c}}$ Activity measured with DCPIP as final electron acceptor 
parental pre $\alpha$ proK-AAO variant. FX7 was expressed at a concentration of $2 \mathrm{mg} / \mathrm{L}$ as a heavily glycosylated protein $(\sim 50 \%$ glycosylation) and possessed biochemical properties comparable to those of PeAAO expressed in E. coli, while $\mathrm{pH}$ and thermal stabilities were significantly enhanced. To further improve $P e$ AAO secretion in S. cerevisiae, in vivo shuffling of the FX7 variant with six other improved variants was combined with subsequent MORPHING of the pre $\alpha$ proK leader sequence (Vina-Gonzalez et al. 2018). The most active clone FX9 with 4 mutations in the pre $\alpha$ proK peptide and 2 mutations, H91N and L170M, in the mature protein was secreted at concentration of $4.5 \mathrm{mg} / \mathrm{L}$ during cultivations in shake flasks. Expression of the FX9 variant in P. pastoris under control of the methanol-inducible $A O X 1$ promoter yielded $25.5 \mathrm{mg} / \mathrm{L}$ of enzyme (final activity of $1378 \mathrm{U} / \mathrm{L}$ ) from a $5 \mathrm{~L}$ fed-batch culture (Vina-Gonzalez et al. 2018). The P. pastorisexpressed FX9 variant showed different kinetic parameters and lower thermal stability than its counterpart expressed in $S$. cerevisiae. These differences were attributed to the poor glycosylation of the FX9 variant expressed in P. pastoris (degree of glycosylation not measurable) compared to heavy glycosylation when expressed in S. cerevisiae (60\% glycosylation). Another Pleurotus AAO from P. sapidus was heterologously expressed in C. cinerea under control of the Agaricus bisporus gpdII promoter up to a volumetric activity of $125 \mathrm{U} /$ L (Galperin et al. 2016). Recently, heterologous expression of $P e A A O 2$ from $P$. eryngii $\mathrm{P} 34$ in $P$. pastoris was reported with an exceptional high yield of $315 \mathrm{mg} / \mathrm{L}$ and a volumetric activity of $7250 \mathrm{U} / \mathrm{L}$ after fed-batch cultivation in $3 \mathrm{~L}$ (Jankowski et al. 2020). Although mature PeAAO2 and the FX9 variant of $P e A A O$ differ only in 9 amino acid residues located on or near the protein's surface, $P e A A O 2$ was much better expressed than FX9 and more stable at acidic and basic $\mathrm{pH}$ values. The higher $\mathrm{pH}$ stability might be due to glycosylation, since $P e A A O 2$ was strongly glycosylated (30\% N-glycosylation) in P. pastoris. Two further AAOs, UmAAO from Ustilago maydis and $\mathrm{r} C$ cAAO from $C$. cinerea, were also expressed in $P$. pastoris (Couturier et al. 2016; Tamaru et al. 2018). UmAAO was secreted with the help of the $\alpha$-factor prepro-leader peptide and expressed with a C-terminal (His) $)_{6}$-tag. Around $1 \mathrm{~g}$ of recombinant $U m \mathrm{AAO}$ per liter of culture medium was produced which is the highest yield of an AAO reported so far. $\mathrm{rC}$ AAO was also fused to the $\alpha$-factor prepro-leader peptide for secretion, but unfortunately no information on expression yields were provided. Kadowaki and coworkers reported on heterologous expression of MtAAOx from T. thermophilus M77 in A. nidulans (Kadowaki et al. 2020). The MtAAOx gene was expressed using a glucoamylase promoter and a heterologous signal peptide. After three chromatographic steps, $8.4 \mathrm{mg}$ of MtAAOx was obtained from $1 \mathrm{~L}$ of culture. The group of Wilkins reported on heterologous expression of an AAO from T. thermophilus in A. nidulans as well (Liu et al. 2020; Pardo-Planas et al.
2017). Process optimization and up-scaling of protein production to 3-L stirred-tank bioreactor resulted in volumetric activity of $1906 \mathrm{U} / \mathrm{L}$ after $48 \mathrm{~h}$ (Liu and Wilkins 2020). However, no sequence information of the enzyme was provided and activity of this enzyme towards veratryl alcohol was solely measured with 2,6-dichlorophenol indophenol (DCPIP) as final electron acceptor. The question if this enzyme is identical or highly similar to MtAAOx remains open.

The second AAO heterologously expressed in E. coli is rAOx from A. terreus MTCC6324 (Chakraborty et al. 2014). rAOx expressed with both $\mathrm{N}$ - and C-terminal (His) $6^{-}$ tag under control of the T7 promoter in E. coli BL21(DE3) predominantly formed inclusion bodies. After purification and in vitro refolding of aporAOx with its cofactor $\mathrm{FAD}$, active rAOx was obtained, but no information on achieved yields were provided.

\section{Biotechnological application}

The ability of AAOs to reduce molecular oxygen to hydrogen peroxide coupled to alcohol oxidation makes them interesting candidates for biotechnological purposes (Fig. 5). On the one hand, AAOs releasing $\mathrm{H}_{2} \mathrm{O}_{2}$ are used to support reactions catalyzed by peroxidases and peroxygenases. On the other hand, AAO-catalyzed oxidation reactions provide a valuable tool for the synthesis of building blocks for chemical synthesis and flavors. Finally, there are processes in which AAOs are applied for both, biocatalytic oxidation and for in situ $\mathrm{H}_{2} \mathrm{O}_{2}$ formation to support other enzymes involved in multi-enzyme cascades for the production of bio-based precursors for polymers. Furthermore, using methods of protein engineering AAOs was optimized for application as effective biocatalysts. In the following, we will give a short overview of the processes and reactions involving AAOs.

\section{Dye decolorization and pulp biobleaching}

AAOs lead to $\mathrm{H}_{2} \mathrm{O}_{2}$ production and hence can support various enzymes during dye decolorization and lignin degradation. Synthetic dyes are widely used in the paper and textile industry causing large amounts of contaminated wastewater. Efficient wastewater treatment is thus of great importance to remove these harmful compounds being toxic to humans and aquatic organisms (Ledakowicz and Pazdzior 2021). Besides physical and chemical treatments, biological methods relying on fungi, bacteria, or isolated enzymes are of high importance. Among others, fungal ligninolytic enzymes, such as laccases, $\mathrm{LiP}$, and $\mathrm{MnP}$, have been broadly used for dye decolorization (Wesenberg et al. 2003). Only one report describes the direct participation of AAO in dye decolorization: AAO isolated from Sphingobacterium sp. ATM caused the degradation of the textile dyes Red 5B, Orange 3R, and Direct Blue GLL 


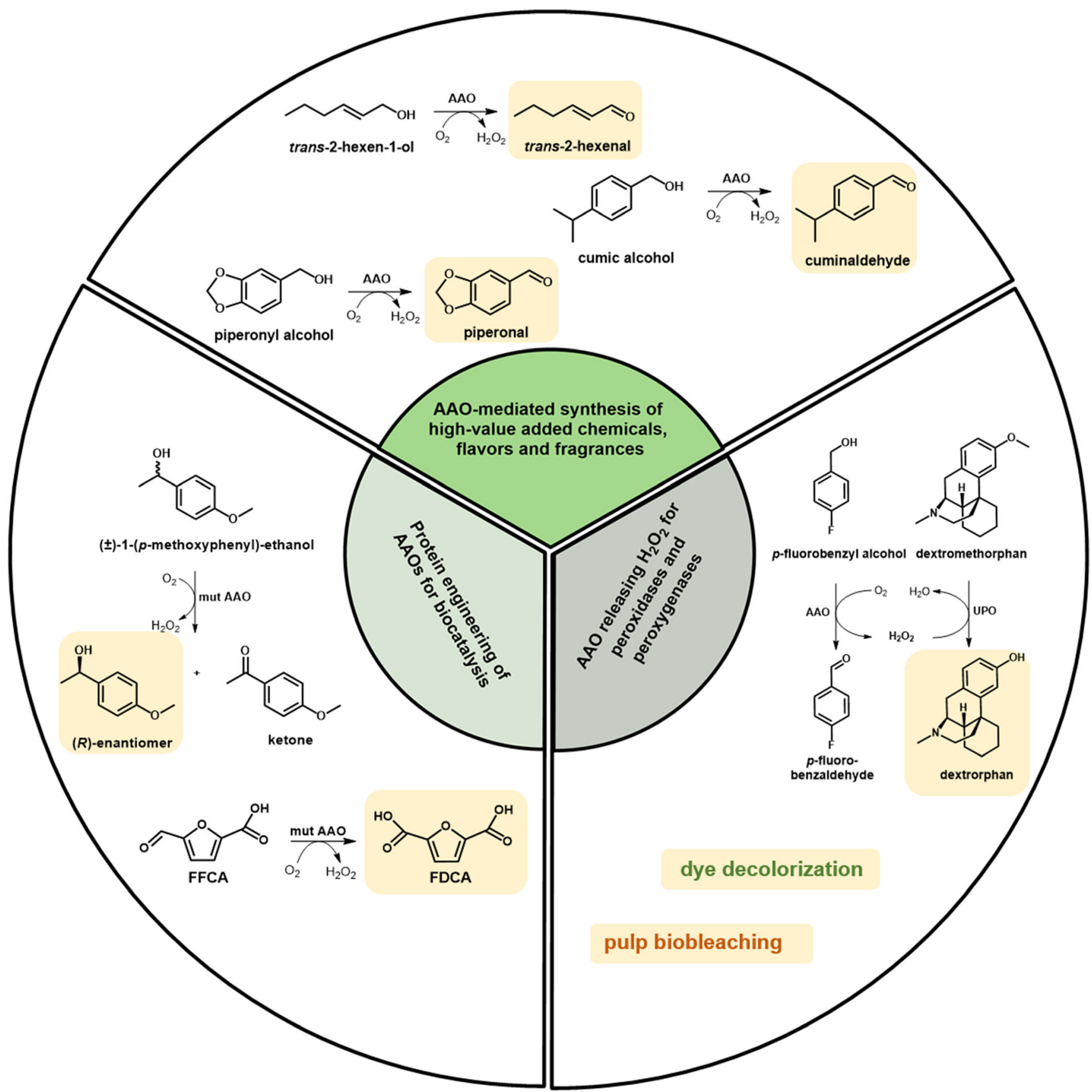

Fig. 5 AAOs for biotechnological purposes

within $8 \mathrm{~h}$ (Tamboli et al. 2011). Other investigations revealed that AAOs contribute to the decolorization process by generating $\mathrm{H}_{2} \mathrm{O}_{2}$ for the dye degrading enzymes. For example, AAO from Geotrichum candidum Decl was not able to degrade textile dyes like Red 5B, but supported its decolorization by delivering $\mathrm{H}_{2} \mathrm{O}_{2}$ to the dye peroxidase DyP. Moreover, $\mathrm{AAO}$ was suggested to prevent the polymerization of dye products produced by DyP peroxidase, which facilitated their further degradation (Kim et al. 2001). A combination of dye decolorizing peroxidase DyP from Mycetinis scorodonius and AAO from $P$. sapidus resulted in a more efficient decolorization of the dye Reactive Blue 5 in comparison to the DyP directly supplied with external $\mathrm{H}_{2} \mathrm{O}_{2}$. This effect was attributed to the low but constant production of $\mathrm{H}_{2} \mathrm{O}_{2}$ by $\mathrm{AAO}$, which allows to overcome the possible DyP inhibition by high $\mathrm{H}_{2} \mathrm{O}_{2}$ concentrations (Galperin et al. 2016). This twoenzyme system does not require additional equipment and online quantification of $\mathrm{H}_{2} \mathrm{O}_{2}$ concentration and thus has a potential to replace the systems for in situ $\mathrm{H}_{2} \mathrm{O}_{2}$ supply like feeding or electrochemical peroxide production.

AAOs have been shown to contribute also to the pulp bleaching process to obtain white paper pulp. Original pulp 
color is impacted by the chromophores of lignin. Thus, a set of hydrolases and oxidoreductases involved in lignin degradation have been tested for removal of these chromophores and pulp lightening. Whereas $P$. cinnabarinus laccase combined with the redox mediator 1-hydroxybenzotriazol (HBT) demonstrated the strongest delignification of pulp, the same laccase without mediator also caused pulp lightening that was increased in the presence of AAO (Sigoillot et al. 2005). Similar to the effect on dye decolorization, the positive effect of AAO was attributed to their ability to prevent repolymerization of the lignin phenoxy radicals produced by laccase (Sigoillot et al. 2005).

\section{Synthesis of flavors and valuable building blocks}

Flavors and fragrances are widely used in food and beverages, as well as in the cosmetic, detergent, and pharmaceutical industries. They are currently mainly produced by chemical synthesis. Due to the increasing consumer demand for "natural" flavors, more and more biotechnological processes relying on enzymes or microorganisms are established for the production of these compounds. Vanillin and benzaldehyde (cherry flavor), the leading compounds in the flavor and fragrance industry, can be formed, for example, via AAOcatalyzed oxidation of the corresponding alcohols, which makes AAOs interesting candidates for the synthesis of flavors and fragrances. For instance, recombinant $P e \mathrm{AAO}$ from $P$. eryngii catalyzes the oxidation of trans-2-hexen-1-ol to trans-2-hexenal, a major component responsible for the fresh flavor of fruits and vegetables. trans-2-Hexenal is widely applied in the flavor and fragrance industry as Green Note in food, beverages, and perfumes. In an attempt to enhance the biocatalytic performance of $\mathrm{PeAAO}$ that can be limited by the poor solubility and low diffusion rates of $\mathrm{O}_{2}$ into the aqueous reaction media, the reaction was conducted in a continuous slug-flow microreactor (van Schie et al. 2018). Additionally, catalase was added to decompose the produced $\mathrm{H}_{2} \mathrm{O}_{2}$ to $\mathrm{H}_{2} \mathrm{O}$ and $\mathrm{O}_{2}$. With this setup, $10 \mathrm{mM}$ trans-2-hexen-1-ol were completely converted to trans-2-hexenal within the residence time of $40 \mathrm{~min}$, which corresponds to a turnover number (TN) of 32,400. By increasing residence time in a longer flow reactor, TNs of over 300,000 were reached (van Schie et al. 2018). Further increase of substrate concentration was however limited by low solubility of trans-2-hexen-1-ol in aqueous media. The use of two liquid-phase systems allowed not only to increase substrate solubility but also to avoid product inhibition (de Almeida et al. 2019). Dodecane and trans-2hexen-1-ol itself as organic phase ensured the best results among the organic solvents tested. At a 1:1 ratio of aqueous to dodecane phase, full conversion of $500 \mathrm{mM}$ trans-2-hexen1-ol was achieved after $24 \mathrm{~h}$. This corresponds to a TN of 650,000. When trans-2-hexen-1-ol was used as organic phase at a 4:1 ratio and both, $P e A A O$ and catalase, were added six times in course of the reaction, 2.6 M trans-2-hexenal were produced within 14 days, which corresponded to a TN of $2,200,000$. These examples demonstrate high robustness of the recombinant $P e A A O$ from $P$. eryngii. In another study, PeAAO2 from $P$. eryngii $\mathrm{P} 34$ was shown to catalyze the oxidation of piperonyl alcohol to piperonal with the second highest catalytic efficiency among the substrates investigated with this enzyme (Fig. 5) (Jankowski et al. 2020). Piperonal, also termed as "heliotropin," has a sweet, floral odor and is used in the perfumery and cosmetic industry, but also in the food industry as vanilla aroma. Piperonal is also used as an intermediate in the production of insecticides, pesticides, and pharmaceutical agents for, e.g., treatment of Alzheimer's disease (Brum et al. 2019; Santos et al. 2004; Wang et al. 2019).

AAOs are also of potential interest for the synthesis of chiral secondary alcohols. Docking of $p$-methoxybenzyl alcohol in the active site of $P e A A O$ has revealed a stereoselective hydride abstraction from the pro- $R \mathrm{C} \alpha$ position (HernandezOrtega et al. 2012b). The stereoselective hydride abstraction from the $S$-enantiomer would lead to the corresponding ketone, while the $R$-enantiomer would remain unaffected. Chiral secondary alcohols are essential building blocks for the production of, e.g., pharmaceutical compounds. However, activity of PeAAO with secondary aromatic alcohols is much lower than with primary alcohols probably due to the narrow substrate access channel. To enhance activity of PeAAO towards secondary alcohols, rational protein design and directed evolution approaches have been applied (Serrano et al. 2019b; Vina-Gonzalez et al. 2019). The PeAAO variant F501A, where phenylalanine limiting substrate diffusion was replaced by the smaller alanine (Hernandez-Ortega et al. 2012b), was used as a starting enzyme for adaptive-protein energy landscape exploration simulations and combinatorial saturation mutagenesis (Serrano et al. 2019b). As a result, the double mutant $\mathrm{I} 500 \mathrm{M} / \mathrm{F} 501 \mathrm{~W}$ with increased activity and stereoselectivity was identified. Introducing the mutations I500M and F501W into the PeAAO variant FX9 with improved secretion (see above), followed by structure-guided evolution including in vivo site-directed recombination as the final step, resulted in the LanDo variant with a more than 800 -fold enhanced activity towards 1-( $p$-methoxyphenyl)-ethanol compared to FX9 (Vina-Gonzalez et al. 2019). The catalytic efficiency $\left(k_{\mathrm{cat}} / K_{\mathrm{m}}\right)$ of the LanDo variant with 1- $(p$ methoxyphenyl)-ethanol was 10 -fold higher than of the I500M/F501W variant. The $S$-enantiomer of racemic $1-(p$ methoxyphenyl)-ethanol was almost completely oxidized by the LanDo variant, which resulted after $2 \mathrm{~h}$ in $R$-enantiomer with $e e>99 \%$. This example demonstrates the potential of AAOs as biocatalyst for the synthesis of chiral secondary alcohols via deracemization.

Another potential field of AAO application lies in the production of compounds with beneficial effects on human health or drug metabolites. PeAAO2 from P. eryngii P34 catalyzes 
the oxidation of cumic alcohol to cuminaldehyde with the highest activity among the substrates tested with this enzyme. Cuminaldehyde is the major constituent of seed oil of Cuminum cyminum (Lee 2005; Li and Jiang 2004) with potential therapeutic effects (Morshedi et al. 2015). For example, cuminaldehyde demonstrated anticancer and antidiabetic properties (Lee 2005; Patil et al. 2013; Tsai et al. 2016).

Recently, a self-sufficient unspecific peroxygenase (UPO)/ aryl-alcohol oxidase biocatalyst for the synthesis of dextrorphan, a human metabolite of the antitussive drug dextromethorphan, was reported (de Santos et al. 2020). The bifunctional fusion consisted of a UPO catalyzing the transformation of dextromethorphan to dextrorphan and an AAO supplying UPO with $\mathrm{H}_{2} \mathrm{O}_{2}$ through the oxidation of primary aromatic alcohols. The engineered SoLo variant of UPO from Agrocybe aegerita with reduced peroxidase activity towards aromatic alcohols and the PeAAO variant FX9 were chosen as fusion partners. At first, several enzyme fusion libraries were constructed consisting of fusions with different partner order and rigid or flexible linkers of different length and compositions between UPO and AAO. For secretion of the fusion construct in S. cerevisiae, two evolved leader sequences were tested, the pre $\alpha$ proK leader peptide for AAO and an evolved signal peptide for UPO. Five UPO-AAO fusions with the highest activities were purified and biochemically characterized. To exclude unwanted interactions of AAO substrates with the UPO partner, several primary aromatic alcohols were tested, and $p$-fluorobenzyl alcohol, 3-methoxybenzyl alcohol, and $p$-methoxybenzyl alcohol led to the best results. By using UPO-AAO fusion with $p$-fluorobenzyl alcohol as sacrificial substrate, $2 \mathrm{mM}$ dextrorphan was obtained from $2 \mathrm{mM}$ dextromethorphan after $24 \mathrm{~h}$, and a TTN of 48,300 was achieved. Since oxidation of $p$-fluorobenzyl alcohol proceeded much faster than dextromethorphan hydroxylation, accumulated $\mathrm{H}_{2} \mathrm{O}_{2}$ most likely inactivated the UPO partner. Feeding of $p$ fluorobenzyl alcohol at $0.5 \mathrm{mM} / \mathrm{h}$ resulted in increased TTN for the synthesis of dextrorphan of over 62,000 . The construction of UPO-AAO fusions for the synthesis of pharmaceutical or chemical compounds further expands the scope of application of AAOs.

\section{Production of bio-based precursors for polymers}

In times of an emerging bioeconomy, the sustainable production of bio-based polymer precursors or platform chemicals becomes more and more important. The use of bio-based 2,5furandicarboxylic acid (FDCA) for the production of the biopolymer polyethylene furanoate (PEF), which could replace polyethylene terephthalate (PET), strongly contributes to establishing a sustainable bioeconomy. The chemical synthesis of FDCA takes place at high temperature and pressure, and involves organic solvents and metal catalysts (Sajid et al. 2018). The oxidation of 5-hydroxymethylfurfural (5-HMF) to FDCA proceeds via 2,5-diformylfuran (DFF) and 5formylfurancarboxylic acid (FFCA). Enzymatic routes from 5-HMF to FDCA, involving, for example, AAO (Fig. 6), can be conducted at ambient temperature without the need of polluting co-solvents. 5-HMF can be obtained by acid-catalyzed dehydration of fructose. Dijkman and Fraaije (2014) described a HMF oxidase (HMFO) from Methylovorus sp. strain MP688, a member of the GMC oxidoreductase family with AAO activity, which was expressed in E. coli and oxidized 5-HMF to FFCA as the main product (92\%), but only minor amounts of FDCA $(8 \%)$ were formed after $5 \mathrm{~h}$ of reaction. Recently, two other HMFOs from P. nitroreducens and Pseudomonas sp. strain 11/12A, both heterologously expressed in $E$. coli, were shown to catalyze oxidation of 5-HMF to up to $99 \%$ FDCA after $96 \mathrm{~h}$ (Vinambres et al. 2020). Carro and coworkers found that $P e \mathrm{AAO}$ expressed in $E$. coli also catalyzed the conversion of 5-HMF to FFCA, but no subsequent oxidation of FFCA to FDCA was detected. To complete the second reaction, an unspecific peroxygenase (UPO) from A. aegerita was added after oxidation of 5-HMF to FFCA yielding 91\% FDCA after $120 \mathrm{~h}$. Another approach was based on the combined action of three fungal enzymes, AAO, UPO, and galactose oxidase (GAO), for the conversion of 5-HMF to FDCA (Karich et al. 2018). AAO catalyzed the oxidation of 5-HMF to DFF along with the production of $\mathrm{H}_{2} \mathrm{O}_{2}$ to be used by UPO for the oxidation of 5-HMF to 5-hydroxymethyl-2-furancarboxylic acid (HMFCA) and to FDCA via the intermediates DFF and FFCA. GAO provided additional $\mathrm{H}_{2} \mathrm{O}_{2}$ for UPO while oxidizing 5-HMF to DFF and particularly HMFCA to FFCA. Starting with $10 \mathrm{mM} 5-\mathrm{HMF}$, $7.9 \mathrm{mM}$ FDCA was formed in this three-enzyme approach after $24 \mathrm{~h}$. Serrano and colleagues recently reported that $P e A A O$ expressed in E. coli catalyzes also the oxidation of FFCA to FDCA, with a 100-fold lower reaction rate compared to 5-HMF or DFF oxidation (Serrano et al. 2019a). They found that the oxidation of FFCA was negatively affected by the presence of $\mathrm{H}_{2} \mathrm{O}_{2}$ particularly at concentrations over $400 \mu \mathrm{M}$, although the enzyme was quite stable in the presence of peroxide. By applying catalase together with PeAAO, 5-HMF was completely oxidized to FDCA after 12 days, which confirmed the inhibitory effect of $\mathrm{H}_{2} \mathrm{O}_{2}$ on FFCA oxidation. When using PeAAO variant $1500 \mathrm{M} / \mathrm{F} 501 \mathrm{~W}$ in catalase-assisted conversion of $15 \mathrm{mM}$ 5-HMF to FDCA, a nearly 2-fold increase in total turnover number (TTN) was achieved.

Vina-Gonzalez and colleagues further engineered $\mathrm{PeAAO}$ for improved conversion of 5-HMF to FDCA (Vina-Gonzalez et al. 2020). Combinatorial saturation mutagenesis of the variant FX9 at positions involved in substrate positioning in the active site, Ile500 and Phe501 in the first round, and Tyr92 and His546 in the second round, leading to the Bantha variant with the additional mutation $\mathrm{F} 501 \mathrm{~W}$ as the most active enzyme. The catalytic efficiency of the Bantha variant was 3fold higher compared to PeAAO wild-type. Formation of FDCA was 6-fold higher when using the Bantha variant and 


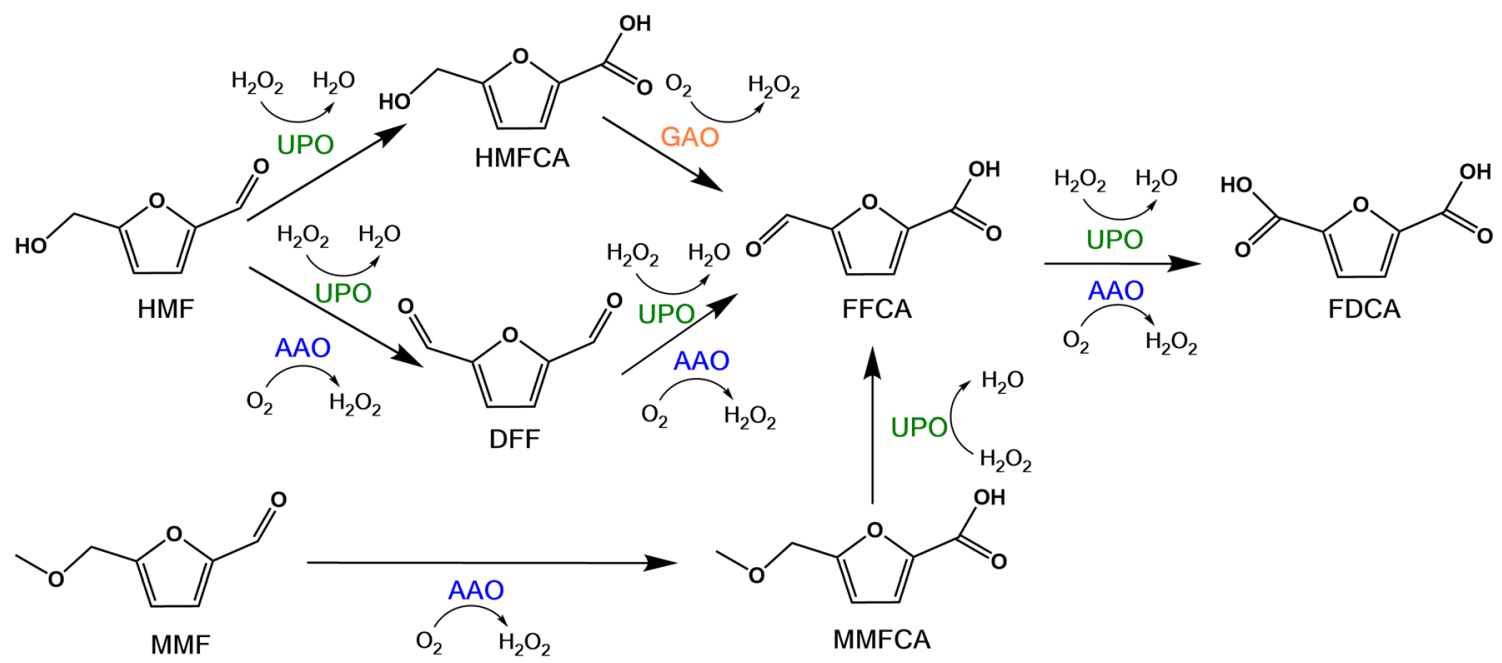

Fig. 6 Enzymatic oxidation of HMF and MMF to FDCA involving AAO

reached $3.0 \%$ after 2 days of reaction starting from $2 \mathrm{mM} \mathrm{5-}$ HMF as substrate.

An alternative route for the production of FDCA is based on 5-methoxymethylfurfural (5-MMF) as starting compound, which is more stable upon storage than 5-HMF. For this route, another three-enzyme system was chosen that consisted of AAO, UPO, and methanol oxidase (MOX) (Carro et al. 2018b). AAO catalyzed the oxidation of 5-MMF to MMFA, while UPO catalyzed the two-step oxidation of MMFA to FDCA via the intermediate FFCA. The activity of UPO was supported by $\mathrm{H}_{2} \mathrm{O}_{2}$ generated by $\mathrm{AAO}$ and additionally in the MOX-mediated oxidation of methanol to formaldehyde. After $120 \mathrm{~h}, 98 \%$ FDCA were formed starting with $1.5 \mathrm{mM} \mathrm{5-}$ MMF. These examples illustrate the usefulness of AAOs for valorization of products from lignocellulose biorefinery.

\section{Concluding remarks and future perspectives}

More than 60 years after the discovery of AAO in $T$. versicolor, a large number of AAO encoding genes were identified in the genomes of many wood-decaying fungi. Their functions in nature and the general catalytic mechanism are considered deciphered, and the reactions catalyzed by AAOs and summarized here impressively demonstrate the high potential of these enzymes for biotechnological purposes. Advances in protein engineering have prompted the construction of AAO variants with altered substrate scope and increased stereoselectivity, which opens new perspectives for synthetic chemistry. Realization of AAO-catalyzed reactions in two-phase systems and in a flow reactor illustrates the high robustness of these biocatalysts and their potential applicability in technical processes at high scale.

However, structural and mechanistic aspects have been tackled mainly based on the crystal structure and molecular modelling of one representative - PeAAO from P. eryngii. In most cases, this enzyme and mutants thereof were successfully used for the synthesis of valuable compounds. So far, only a few other AAOs were purified and characterized in respect to their biochemical properties and substrate spectra. Since AAO sequences demonstrate low identity, three-dimensional structures of other members would provide more insights into catalysis and substrate recognition, and allow to rationalize differences in substrate spectra and properties of these enzymes. In 2020, the second structure of an AAO originating from T. thermophilus has been solved, which revealed several significant differences compared to the structure of PeAAO. Structural information on other AAOs and their comparison could build a broader background for enzyme engineering to promote recognition and oxidation of industrially relevant compounds with high activity and selectivity. However, heterologous expression of AAOs in recombinant hosts remains a challenging task and seems to limit their broader application and protein engineering. Although significant efforts have been undertaken to enhance heterologous expression of AAOs, no straightforward strategy has been established yet. Engineering of the signal peptide facilitated protein secretion of PeAAO in $S$. cerevisiae in the culture medium, but also mutations in the protein sequence positively influenced gene expression (Vina-Gonzalez et al. 2015, 2018). Another intriguing question is why expression of PeAAO in $P$. pastoris failed, whereas the homologous $P e A A O 2$ with only seven different amino acids was expressed at a concentration of $315 \mathrm{mg} / \mathrm{L}$. Obviously, more deep understanding of the effect of these amino acids on transcription, translation, protein folding, secretion, and stability is required and will remain in focus of future studies.

The scope of AAO applications can be expanded by their exploiting as supplier of $\mathrm{H}_{2} \mathrm{O}_{2}$ for various peroxide-dependent enzymes. A contribution to enzyme-mediated delignification of plant biomass in biorefinery concepts seems plausible since ligninolytic peroxidases relying on $\mathrm{H}_{2} \mathrm{O}_{2}$ play a major role in 
lignin degradation in nature. Along with their use in biobleaching and biopulping in the pulp and paper industry, AAOs might also support peroxidases in polymer synthesis, bioremediation of phenolic compounds, peroxidase-based biosensors, and biocatalysis (Regalado et al. 2004). Reaction engineering will focus on developing substrate-feeding strategies to control the level of $\mathrm{H}_{2} \mathrm{O}_{2}$ released by AAOs in order to avoid its negative effect on heme-containing peroxidases and peroxygenases. Combinations of AAOs with other biocatalysts in multi-step cascade reactions offer alternative routes for the synthesis of various molecules and provide exciting future perspectives to access novel compounds that cannot be synthesized by classical chemical routes.

Thus, the concepts described in this review build a solid background for further development of AAOs towards applications with efficiencies approaching economic viability.

Author contribution VU and KK conceived and wrote the manuscript. $\mathrm{VU}$ and KK conceived and designed the figures. All authors read and approved the final manuscript.

Funding Open access funding enabled and organized by Projekt DEAL. The scientific activities of the Bioeconomy Science Center were financially supported by the Ministry of Innovation, Science and Research of North Rhine-Westphalia, Germany, within the framework of the NRWStrategieprojekt BioSC (No. 313/323-400-002 13).

Availability of data and material All data on which the conclusions were drawn are presented in this study.

Code availability Not applicable.

\section{Declarations}

Ethical approval This article does not contain any studies with human participants or animals performed by any of the authors.

\section{Consent to participate Not applicable.}

Consent for publication Not applicable.

Conflict of interest The authors declare no competing interests.

Open Access This article is licensed under a Creative Commons Attribution 4.0 International License, which permits use, sharing, adaptation, distribution and reproduction in any medium or format, as long as you give appropriate credit to the original author(s) and the source, provide a link to the Creative Commons licence, and indicate if changes were made. The images or other third party material in this article are included in the article's Creative Commons licence, unless indicated otherwise in a credit line to the material. If material is not included in the article's Creative Commons licence and your intended use is not permitted by statutory regulation or exceeds the permitted use, you will need to obtain permission directly from the copyright holder. To view a copy of this licence, visit http://creativecommons.org/licenses/by/4.0/.

\section{References}

Ahmad M, Hirz M, Pichler H, Schwab H (2014) Protein expression in Pichia pastoris: recent achievements and perspectives for heterologous protein production. Appl Microbiol Biotechnol 98(12):53015317. https://doi.org/10.1007/s00253-014-5732-5

Asada Y, Watanabe A, Ohtsu Y, Kuwahara M (1995) Purification and characterization of an aryl-alcohol oxidase from the lignindegrading basidiomycete Phanerochaete chrysosporium. Biosci Biotechnol Biochem 59(7):1339-1341. https://doi.org/10.1271/ bbb.59.1339

Becker J, Wittmann C (2019) A field of dreams: lignin valorization into chemicals, materials, fuels, and health-care products. Biotechnol Adv 37(6):107360. https://doi.org/10.1016/j.biotechadv.2019.02. 016

Berka RM, Grigoriev IV, Otillar R, Salamov A, Grimwood J, Reid I, Ishmael N, John T, Darmond C, Moisan MC, Henrissat B, Coutinho PM, Lombard V, Natvig DO, Lindquist E, Schmutz J, Lucas S, Harris P, Powlowski J, Bellemare A, Taylor D, Butler G, de Vries RP, Allijn IE, van den Brink J, Ushinsky S, Storms R, Powell AJ, Paulsen IT, Elbourne LD, Baker SE, Magnuson J, Laboissiere S, Clutterbuck AJ, Martinez D, Wogulis M, de Leon AL, Rey MW, Tsang A (2011) Comparative genomic analysis of the thermophilic biomass-degrading fungi Myceliophthora thermophila and Thielavia terrestris. Nat Biotechnol 29(10):922-927. https:// doi.org/10.1038/nbt.1976

Bhat SG, Vaidyanathan CS (1976) Purification and properties of L-4hydroxymandelate oxidase from Pseudomonas convexa. Eur J Biochem 68(2):323-331. https://doi.org/10.1111/j.1432-1033. 1976.tb10818.x

Bourbonnais R, Paice MG (1988) Veratryl alcohol oxidases from the lignin-degrading basidiomycete Pleurotus sajor-caju. Biochem J 255(2):445-450. https://doi.org/10.1042/bj2550445

Brückmann M, Termonia A, Pasteels JM, Hartmann T (2002) Characterization of an extracellular salicyl alcohol oxidase from larval defensive secretions of Chrysomela populi and Phratora vitellinae (Chrysomelina). Insect Biochem Mol Biol 32(11):15171523. https://doi.org/10.1016/s0965-1748(02)00072-3

Brum JOC, Neto DCF, de Almeida JSFD, Lima JA, Kuca K, França TCC, Figueroa-Villar JD (2019) Synthesis of new quinolinepiperonal hybrids as potential drugs against Alzheimer's disease. Int J Mol Sci 20(16):3944. https://doi.org/10.3390/ijms20163944

Bugg TDH, Ahmad M, Hardiman EM, Rahmanpour R (2011) Pathways for degradation of lignin in bacteria and fungi. Nat Prod Rep 28(12): 1883-1896. https://doi.org/10.1039/c1np00042j

Carro J, Martinez-Julvez M, Medina M, Martinez AT, Ferreira P (2017) Protein dynamics promote hydride tunnelling in substrate oxidation by aryl-alcohol oxidase. Phys Chem Chem Phys 19(42):2866628675. https://doi.org/10.1039/c7cp05904c

Carro J, Amengual-Rigo P, Sancho F, Medina M, Guallar V, Ferreira P, Martinez AT (2018a) Multiple implications of an active site phenylalanine in the catalysis of aryl-alcohol oxidase. Sci Rep 8(1):8121. https://doi.org/10.1038/s41598-018-26445-x

Carro J, Fernandez-Fueyo E, Fernandez-Alonso C, Canada J, Ullrich R, Hofrichter M, Alcalde M, Ferreira P, Martinez AT (2018b) Selfsustained enzymatic cascade for the production of 2,5furandicarboxylic acid from 5-methoxymethylfurfural. Biotechnol Biofuels 11:10. https://doi.org/10.1186/s13068-018-1091-2

Carro J, Ferreira P, Martinez AT, Gadda G (2018c) Stepwise hydrogen atom and proton transfers in dioxygen reduction by aryl-alcohol oxidase. Biochemistry 57(11):1790-1797. https://doi.org/10.1021/ acs.biochem.8b00106

Casieri L, Varese GC, Anastasi A, Prigione V, Svobodova K, Marchisio VF, Novotny C (2008) Decolorization and detoxication of reactive 
industrial dyes by immobilized fungi Trametes pubescens and Pleurotus ostreatus. Folia Microbiol 53(1):44-52. https://doi.org/ 10.1007/s12223-008-0006-1

Cavener DR (1992) GMC Oxidoreductases - a newly defined family of homologous proteins with diverse catalytic activities. J Mol Biol 223(3):811-814. https://doi.org/10.1016/0022-2836(92)90992-S

Chakraborty M, Goel M, Chinnadayyala SR, Dahiya UR, Ghosh SS, Goswami P (2014) Molecular characterization and expression of a novel alcohol oxidase from Aspergillus terreus MTCC6324. PLoS One 9(4):19. https://doi.org/10.1371/journal.pone.0095368

Couturier M, Mathieu Y, Li A, Navarro D, Drula E, Haon M, Grisel S, Ludwig R, Berrin JG (2016) Characterization of a new aryl-alcohol oxidase secreted by the phytopathogenic fungus Ustilago maydis. Appl Microbiol Biotechnol 100(2):697-706. https://doi.org/10. 1007/s00253-015-7021-3

Daniel G, Volc J, Filonova L, Plíhal O, Kubátová E, Halada P (2007) Characteristics of Gloeophyllum trabeum alcohol oxidase, an extracellular source of $\mathrm{H}_{2} \mathrm{O}_{2}$ in brown rot decay of wood. Appl Environ Microbiol 73(19):6241-6253. https://doi.org/10.1128/aem.0097707

de Almeida TP, van Schie MMCH, Ma A, Tieves F, Younes SHH, Fernandez-Fueyo E, Arends IWCE, Riul A, Hollmann F (2019) Efficient aerobic oxidation of trans-2-hexen-1-ol using the aryl alcohol oxidase from Pleurotus eryngii. Adv Synth Catal 361(11): 2668-2672. https://doi.org/10.1002/adsc.201801312

de Gonzalo G, Colpa DI, Habib MHM, Fraaije MW (2016) Bacterial enzymes involved in lignin degradation. J Biotechnol 236:110 119. https://doi.org/10.1016/j.jbiotec.2016.08.011

de Jong E, de Vries FP, Field JA, van der Zwan RP, de Bont JAM (1992a) Isolation and screening of basidiomycetes with high peroxidative activity. Mycol Res 96:1098-1104. https://doi.org/10.1016/S09537562(09)80121-4

de Jong E, van Berkel WJ, van der Zwan RP, de Bont JA (1992b) Purification and characterization of vanillyl-alcohol oxidase from Penicillium simplicissimum. A novel aromatic alcohol oxidase containing covalently bound FAD. Eur J Biochem 208(3):651-657. https://doi.org/10.1111/j.1432-1033.1992.tb17231.x

de Jong E, Cazemier AE, Field JA, de Bont JA (1994) Physiological role of chlorinated aryl alcohols biosynthesized de novo by the white rot fungus Bjerkandera sp. strain BOS55. Appl Environ Microbiol 60(1):271-277. https://doi.org/10.1128/AEM.60.1.271-277.1994

de Santos PG, Lazaro S, Vina-Gonzalez J, Hoang MD, Sanchez-Moreno I, Glieder A, Hollmann F, Alcalde M (2020) Evolved peroxygenasearyl alcohol oxidase fusions for self-sufficient oxyfunctionalization reactions. ACS Catal 10(22):13524-13534. https://doi.org/10.1021/ acscatal.0c03029

Dijkman WP, Fraaije MW (2014) Discovery and characterization of a 5hydroxymethylfurfural oxidase from Methylovorus sp. strain MP688. Appl Environ Microbiol 80(3):1082-1090. https://doi.org/ 10.1128/aem.03740-13

Dijkman WP, de Gonzalo G, Mattevi A, Fraaije MW (2013) Flavoprotein oxidases: classification and applications. Appl Microbiol Biotechnol 97(12):5177-5188. https://doi.org/10.1007/s00253-013-4925-7

Ewing TA, Dijkman WP, Vervoort JM, Fraaije MW, van Berkel WJ (2014) The oxidation of thiols by flavoprotein oxidases: a biocatalytic route to reactive thiocarbonyls. Angew Chem Int Ed Eng 53(48):13206-13209. https://doi.org/10.1002/anie.201407520

Ewing TA, Gygli G, Fraaije MW, van Berkel WJH (2020) Vanillyl alcohol oxidase. Enzymes 47:87-116. https://doi.org/10.1016/bs.enz. 2020.05 .003

Farmer VC, Henderson MEK, Russell JD (1960) Aromatic-alcoholoxidase activity in the growth medium of Polystictus versicolor. Biochem J 74(2):257-262. https://doi.org/10.1042/bj0740257

Fernandez IS, Ruiz-Duenas FJ, Santillana E, Ferreira P, Martinez MJ, Martinez AT, Romero A (2009) Novel structural features in the GMC family of oxidoreductases revealed by the crystal structure of fungal aryl-alcohol oxidase. Acta Crystallogr D Biol Crystallogr 65(Pt 11):1196-1205. https://doi.org/10.1107/S0907444909035860

Ferreira P, Medina M, Guillen F, Martinez MJ, Van Berkel WJH, Martinez AT (2005) Spectral and catalytic properties of arylalcohol oxidase, a fungal flavoenzyme acting on polyunsaturated alcohols. Biochem J 389:731-738. https://doi.org/10.1042/ Bj20041903

Ferreira P, Ruiz-Duenas FJ, Martinez MJ, van Berkel WJ, Martinez AT (2006) Site-directed mutagenesis of selected residues at the active site of aryl-alcohol oxidase, an $\mathrm{H}_{2} \mathrm{O}_{2}$-producing ligninolytic enzyme. FEBS J 273(21):4878-4888. https://doi.org/10.1111/j.17424658.2006.05488.x

Ferreira P, Hernandez-Ortega A, Herguedas B, Rencoret J, Gutierrez A, Martinez MJ, Jimenez-Barbero J, Medina M, Martinez AT (2010) Kinetic and chemical characterization of aldehyde oxidation by fungal aryl-alcohol oxidase. Biochem J 425:585-593. https://doi.org/ 10.1042/Bj20091499

Ferreira P, Carro J, Serrano A, Martinez AT (2015a) A survey of genes encoding $\mathrm{H}_{2} \mathrm{O}_{2}$-producing GMC oxidoreductases in 10 Polyporales genomes. Mycologia 107(6):1105-1119. https://doi.org/10.3852/ $15-027$

Ferreira P, Hernandez-Ortega A, Lucas F, Carro J, Herguedas B, Borrelli KW, Guallar V, Martinez AT, Medina M (2015b) Aromatic stacking interactions govern catalysis in aryl-alcohol oxidase. FEBS J 282(16):3091-3106. https://doi.org/10.1111/febs.13221

Galperin I, Javeed A, Luig H, Lochnit G, Ruhl M (2016) An aryl-alcohol oxidase of Pleurotus sapidus: heterologous expression, characterization, and application in a 2-enzyme system. Appl Microbiol Biotechnol 100(18):8021-8030. https://doi.org/10.1007/s00253016-7567-8

Goetghebeur M, Nicolas M, Brun S, Galzy P (1992) Purification and properties of benzyl alcohol oxidase from Botrytis cinerea. Biosci Biotechnol Biochem 56(2):298-303. https://doi.org/10.1271/bbb. 56.298

Guillen F, Evans CS (1994) Anisaldehyde and veratraldehyde acting as redox cycling agents for $\mathrm{H}_{2} \mathrm{O}_{2}$ production by Pleurotus eryngii. Appl Environ Microbiol 60(8):2811-2817

Guillen F, Martinez AT, Martinez MJ (1990) Production of hydrogenperoxide by aryl-alcohol oxidase from the ligninolytic fungus Pleurotus eryngii. Appl Microbiol Biotechnol 32(4):465-469. https://doi.org/10.1007/Bf00903784

Guillen F, Martinez AT, Martinez MJ (1992) Substrate-specificity and properties of the aryl-alcohol oxidase from the ligninolytic fungus Pleurotus eryngii. Eur J Biochem 209(2):603-611. https://doi.org/ 10.1111/j.1432-1033.1992.tb17326.x

Hall M (2020) Flavoenzymes for biocatalysis. Enzymes 47:37-62. https://doi.org/10.1016/bs.enz.2020.05.001

Hammel KE (1997) Fungal degradation of lignin. In: Cadisch G, Giller KE (eds) Driven by nature: plant litter quality and decomposition. CAB International, Oxon, pp 33-45

Hernandez-Ortega A, Borrelli K, Ferreira P, Medina M, Martinez AT, Guallar V (2011a) Substrate diffusion and oxidation in GMC oxidoreductases: an experimental and computational study on fungal aryl-alcohol oxidase. Biochem J 436(2):341-350. https://doi.org/10. 1042/BJ20102090

Hernandez-Ortega A, Lucas F, Ferreira P, Medina M, Guallar V, Martinez AT (2011b) Modulating O2 reactivity in a fungal flavoenzyme: involvement of aryl-alcohol oxidase Phe-501 contiguous to catalytic histidine. J Biol Chem 286(47):41105-41114. https://doi.org/10.1074/jbc.M111.282467

Hernandez-Ortega A, Ferreira P, Martinez AT (2012a) Fungal arylalcohol oxidase: a peroxide-producing flavoenzyme involved in lignin degradation. Appl Microbiol Biotechnol 93(4):1395-1410. https://doi.org/10.1007/s00253-011-3836-8

Hernandez-Ortega A, Ferreira P, Merino P, Medina M, Guallar V, Martinez AT (2012b) Stereoselective hydride transfer by aryl- 
alcohol oxidase, a member of the GMC superfamily. ChemBioChem 13(3):427-435. https://doi.org/10.1002/cbic. 201100709

Hernandez-Ortega A, Lucas F, Ferreira P, Medina M, Guallar V, Martinez AT (2012c) Role of active site histidines in the two halfreactions of the aryl-alcohol oxidase catalytic cycle. Biochemistry 51(33):6595-6608. https://doi.org/10.1021/bi300505z

Iida K, Cox-Foster DL, Yang XL, Ko WY, Cavener DR (2007) Expansion and evolution of insect GMC oxidoreductases. BMC Evol Biol 7:75. https://doi.org/10.1186/1471-2148-7-75

Jankowski N, Koschorreck K, Urlacher VB (2020) High-level expression of aryl-alcohol oxidase 2 from Pleurotus eryngii in Pichia pastoris for production of fragrances and bioactive precursors. Appl Microbiol Biotechnol 104(21):9205-9218. https://doi.org/10.1007/ s00253-020-10878-4

Kadowaki MAS, Higasi PMR, de Godoy MO, de Araujo EA, Godoy AS, Prade RA, Polikarpov I (2020) Enzymatic versatility and thermostability of a new aryl-alcohol oxidase from Thermothelomyces thermophilus M77. Biochim Biophys Acta 1864(10):129681. https://doi.org/10.1016/j.bbagen.2020.129681

Karich A, Kleeberg SB, Ullrich R, Hofrichter M (2018) Enzymatic preparation of 2,5-furandicarboxylic acid (FDCA)-a substitute of terephthalic acid-by the joined action of three fungal enzymes. Microorganisms 6(1):12. https://doi.org/10.3390/ microorganisms6010005

Kim SJ, Suzuki N, Uematsu Y, Shoda M (2001) Characterization of aryl alcohol oxidase produced by dye-decolorizing fungus, Geotrichum candidum Dec1. J Biosci Bioeng 91(2):166-172. https://doi.org/10. 1263/jbb.91.166

Large AT, Connock MJ (1993) Aromatic alcohol oxidase and aldehyde oxidase activities in the digestive gland of 3 species of terrestrial gastropod (Helix aspersa, Arion ater, Limax flavus). Comp Biochem Physiol B: Biochem Mol Biol 104(3):489-491. https:// doi.org/10.1016/0305-0491(93)90271-6

Ledakowicz S, Pazdzior K (2021) Recent achievements in dyes removal focused on advanced oxidation processes integrated with biological methods. Molecules 26(4):870. https://doi.org/10.3390/ molecules 26040870

Lee HS (2005) Cuminaldehyde: aldose reductase and $\alpha$-glucosidase inhibitor derived from Cuminum cyminum L. seeds. J Agric Food Chem 53:2446-2450. https://doi.org/10.1021/jf048451g

Levasseur A, Drula E, Lombard V, Coutinho PM, Henrissat B (2013) Expansion of the enzymatic repertoire of the CAZy database to integrate auxiliary redox enzymes. Biotechnol Biofuels 6:41. https://doi.org/10.1186/1754-6834-6-41

Levasseur A, Lomascolo A, Chabrol O, Ruiz-Duenas FJ, Boukhris-Uzan E, Piumi F, Kues U, Ram AF, Murat C, Haon M, Benoit I, Arfi Y, Chevret D, Drula E, Kwon MJ, Gouret P, Lesage-Meessen L, Lombard V, Mariette J, Noirot C, Park J, Patyshakuliyeva A, Sigoillot JC, Wiebenga A, Wosten HA, Martin F, Coutinho PM, de Vries RP, Martinez AT, Klopp C, Pontarotti P, Henrissat B, Record E (2014) The genome of the white-rot fungus Pycnoporus cinnabarinus: a basidiomycete model with a versatile arsenal for lignocellulosic biomass breakdown. BMC Genomics 15:486. https://doi.org/10.1186/1471-2164-15-486

Li R, Jiang ZT (2004) Chemical composition of the essential oil of Cuminum cyminum L. from China. Flavour Fragrance J 19:311313. https://doi.org/10.1002/ffj.1302

Liu ES, Wilkins MR (2020) Process optimization and scale-up production of fungal aryl alcohol oxidase from genetically modified Aspergillus nidulans in stirred-tank bioreactor. Bioresour Technol 315:123792. https://doi.org/10.1016/j.biortech.2020.123792

Liu ES, Li MX, Abdella A, Wilkins MR (2020) Development of a costeffective medium for submerged production of fungal aryl alcohol oxidase using a genetically modified Aspergillus nidulans strain.
Bioresour Technol 305:123038. https://doi.org/10.1016/j.biortech. 2020.123038

Mann V, Large A, Khan S, Malik Z, Connock MJ (1989) Aromatic alcohol oxidase - a new membrane-bound $\mathrm{H}_{2} \mathrm{O}_{2}$-generating enzyme in alimentary tissues of the slug Arion ater. J Exp Zool 251(3):265274. https://doi.org/10.1002/jez.1402510302

Martin C, Binda C, Fraaije MW, Mattevi A (2020) The multipurpose family of flavoprotein oxidases. Enzymes 47:63-86. https://doi. org/10.1016/bs.enz.2020.05.002

Martinez AT, Rencoret J, Nieto L, Jimenez-Barbero J, Gutierrez A, del Rio JC (2011) Selective lignin and polysaccharide removal in natural fungal decay of wood as evidenced by in situ structural analyses. Environ Microbiol 13(1):96-107. https://doi.org/10.1111/j.14622920.2010.02312.x

Mathieu Y, Piumi F, Valli R, Aramburu JC, Ferreira P, Faulds CB, Record E (2016) Activities of secreted aryl alcohol quinone oxidoreductases from Pycnoporus cinnabarinus provide insights into fungal degradation of plant biomass. Appl Environ Microbiol 82(8): 2411-2423. https://doi.org/10.1128/Aem.03761-15

Morshedi D, Aliakbari F, Tayaranian-Marvian A, Fassihi A, PanMontojo F, Pérez-Sánchez H (2015) Cuminaldehyde as the major component of Cuminum cyminum, a natural aldehyde with inhibitory effect on alpha-synuclein fibrillation and cytotoxicity. J Food Sci 80:H2336-H2345. https://doi.org/10.1111/1750-3841.13016

Muheim A, Leisola MSA, Schoemaker HE (1990a) Aryl-alcohol oxidase and lignin peroxidase from the white-rot fungus Bjerkandera adusta. J Biotechnol 13(2-3):159-167. https://doi.org/10.1016/ 0168-1656(90)90101-G

Muheim A, Waldner R, Leisola MSA, Fiechter A (1990b) An extracellular aryl-alcohol oxidase from the white-rot fungus Bjerkandera adusta. Enzym Microb Technol 12(3):204-209. https://doi.org/10. 1016/0141-0229(90)90039-S

Pardo-Planas O, Prade RA, Wilkins MR (2017) High-yield production of aryl alcohol oxidase under limited growth conditions in small-scale systems using a mutant Aspergillus nidulans strain. J Ind Microbiol Biotechnol 44(2):247-257. https://doi.org/10.1007/s10295-0161884-x

Patil SB, Takalikar SS, Joglekar MM, Haldavnekar VS, Arvindekar AU (2013) Insulinotropic and $\beta$-cell protective action of cuminaldehyde, cuminol and an inhibitor isolated from Cuminum cyminum in streptozotocin-induced diabetic rats. Br J Nutr 110: 1434-1443. https://doi.org/10.1017/S0007114513000627

Paul CE, Eggerichs D, Westphal AH, Tischler D, van Berkel WJH (2021) Flavoprotein monooxygenases: versatile biocatalysts. Biotechnol Adv:107712. https://doi.org/10.1016/j.biotechadv.2021.107712

Regalado V, Perestelo F, Rodriguez A, Carnicero A, Sosa FJ, De la Fuente G, Falcon MA (1999) Activated oxygen species and two extracellular enzymes: laccase and aryl-alcohol oxidase, novel for the lignin-degrading fungus Fusarium proliferatum. Appl Microbiol Biotechnol 51(3):388-390. https://doi.org/10.1007/s002530051407

Riyadi FA, Tahir AA, Yusof N, Sabri NSA, Noor M, Akhir F, Othman N, Zakaria Z, Hara H (2020) Enzymatic and genetic characterization of lignin depolymerization by Streptomyces sp. S6 isolated from a tropical environment. Sci Rep 10(1):9. https://doi.org/10.1038/ s41598-020-64817-4

Romero E, Ferreira P, Martinez AT, Martinez MJ (2009) New oxidase from Bjerkandera arthroconidial anamorph that oxidizes both phenolic and nonphenolic benzyl alcohols. Biochim Biophys Acta 1794(4):689-697. https://doi.org/10.1016/j.bbapap.2008.11.013

Ruiz-Duenas FJ, Ferreira P, Martinez MJ, Martinez AT (2006) In vitro activation, purification, and characterization of Escherichia coli expressed aryl-alcohol oxidase, a unique $\mathrm{H}_{2} \mathrm{O}_{2}$-producing enzyme. Protein Expr Purif 45(1):191-199. https://doi.org/10.1016/j.pep. 2005.06.003

Sajid M, Zhao XB, Liu DH (2018) Production of 2,5-furandicarboxylic acid (FDCA) from 5-hydroxymethylfurfural (HMF): recent progress 
focusing on the chemical-catalytic routes. Green Chem 20(24): 5427-5453. https://doi.org/10.1039/c8gc02680g

Sannia G, Limongi P, Cocca E, Buonocore F, Nitti G, Giardina P (1991) Purification and characterization of a veratryl alcohol oxidase enzyme from the lignin degrading basidiomycete Pleurotus ostreatus. Biochim Biophys Acta 1073(1):114-119. https://doi.org/10.1016/ 0304-4165(91)90190-r

Santos AS, Pereira N, Da Silva IM, Sarquis MIM, Antunes OAC (2004) Peroxidase catalyzed microbiological oxidation of isosafrol into piperonal. Process Biochem 39:2269-2275. https://doi.org/10.1016/j. procbio.2003.11.019

Serrano A, Calvino E, Carro J, Sanchez-Ruiz MI, Canada FJ, Martinez AT (2019a) Complete oxidation of hydroxymethylfurfural to furandicarboxylic acid by aryl-alcohol oxidase. Biotechnol Biofuels 12(1):217. https://doi.org/10.1186/s13068-019-1555-z

Serrano A, Sancho F, Vina-Gonzalez J, Carro J, Alcalde M, Guallar V, Martinez AT (2019b) Switching the substrate preference of fungal aryl-alcohol oxidase: towards stereoselective oxidation of secondary benzyl alcohols. Catal Sci Technol 9(3):833-841. https://doi.org/10. 1039/c8cy02447b

Serrano A, Carro J, Martinez AT (2020) Reaction mechanisms and applications of aryl-alcohol oxidase. Enzymes 47:167-192. https://doi. org/10.1016/bs.enz.2020.05.005

Sigoillot C, Camarero S, Vidal T, Record E, Asther M, Perez-Boada M, Martinez MJ, Sigoillot JC, Asther M, Colom JF, Martinez AT (2005) Comparison of different fungal enzymes for bleaching high-quality paper pulps. J Biotechnol 115(4):333-343. https://doi. org/10.1016/j.jbiotec.2004.09.006

Sucharitakul J, Prongjit M, Haltrich D, Chaiyen P (2008) Detection of a C4a-hydroperoxyflavin intermediate in the reaction of a flavoprotein oxidase. Biochemistry 47(33):8485-8490. https://doi.org/10.1021/ bi801039d

Sützl L, Laurent CVFP, Abrera AT, Schütz G, Ludwig R, Haltrich D (2018) Multiplicity of enzymatic functions in the CAZy AA3 family. Appl Microbiol Biotechnol 102:2477-2492. https://doi.org/10. 1007/s00253-018-8784-0

Sützl L, Foley G, Gillam EMJ, Boden M, Haltrich D (2019) The GMC superfamily of oxidoreductases revisited: analysis and evolution of fungal GMC oxidoreductases. Biotechnol Biofuels 12:118. https:// doi.org/10.1186/s13068-019-1457-0

Tamaru Y, Umezawa K, Yoshida M (2018) Characterization of an arylalcohol oxidase from the plant saprophytic basidiomycete Coprinopsis cinerea with broad substrate specificity against aromatic alcohols. Biotechnol Lett 40(7):1077-1086. https://doi.org/10. 1007/s10529-018-2534-3

Tamboli DP, Telke AA, Dawkar VV, Jadhav SB, Govindwar SP (2011) Purification and characterization of bacterial aryl alcohol oxidase from Sphingobacterium sp. ATM and its uses in textile dye decolorization. Biotechnol Bioprocess Eng 16(4):661-668. https://doi. org/10.1007/s12257-011-0031-9

Toplak M, Matthews A, Teufel R (2021) The devil is in the details: the chemical basis and mechanistic versatility of flavoprotein monooxygenases. Arch Biochem Biophys 698:108732. https://doi. org/10.1016/j.abb.2020.108732

Tsai KD, Liu YH, Chen TW, Yang SM, Wong HY, Cherng J, Chou KS, Cherng JM (2016) Cuminaldehyde from Cinnamomum verum induces cell death through targeting topoisomerase 1 and 2 in human colorectal adenocarcinoma COLO 205 cells. Nutrients 8:1-17. https://doi.org/10.3390/nu8060318

van Schie MMCH, de Almeida TP, Laudadio G, Tieves F, FernandezFueyo E, Noel T, Arends IWCE, Hollmann F (2018) Biocatalytic synthesis of the Green Note trans-2-hexenal in a continuous-flow microreactor. Beilstein J Org Chem 14:697-703. https://doi.org/10. 3762/bjoc. 14.58

Varela E, Bockle B, Romero A, Martinez AT, Martinez MJ (2000) Biochemical characterization, cDNA cloning and protein crystallization of aryl-alcohol oxidase from Pleurotus pulmonarius. Biochim Biophys Acta 1476(1):129-138. https://doi.org/10.1016/ S0167-4838(99)00227-7

Varela E, Guillen F, Martinet AT, Martinez MJ (2001) Expression of Pleurotus eryngii aryl-alcohol oxidase in Aspergillus nidulans: purification and characterization of the recombinant enzyme. Biochim Biophys Acta 1546(1):107-113. https://doi.org/10.1016/S01674838(00)00301-0

Vina-Gonzalez J, Alcalde M (2020) Directed evolution of the arylalcohol oxidase: beyond the lab bench. Comput Struct Biotechnol J 18:1800-1810. https://doi.org/10.1016/j.csbj.2020.06.037

Vina-Gonzalez J, Gonzalez-Perez D, Ferreira P, Martinez AT, Alcalde M (2015) Focused directed evolution of aryl-alcohol oxidase in Saccharomyces cerevisiae by using chimeric signal peptides. Appl Environ Microbiol 81(18):6451-6462. https://doi.org/10.1128/ Aem.01966-15

Vina-Gonzalez J, Elbl K, Ponte X, Valero F, Alcalde M (2018) Functional expression of aryl-alcohol oxidase in Saccharomyces cerevisiae and Pichia pastoris by directed evolution. Biotechnol Bioeng 115(7):1666-1674. https://doi.org/10.1002/bit.26585

Vina-Gonzalez J, Jimenez-Lalana D, Sancho F, Serrano A, Martinez AT, Guallar V, Alcalde M (2019) Structure-guided evolution of aryl alcohol oxidase from Pleurotus eryngii for the selective oxidation of secondary benzyl alcohols. Adv Synth Catal 361(11):2514-2525. https://doi.org/10.1002/adsc.201900134

Vina-Gonzalez J, Martinez AT, Guallar V, Alcalde M (2020) Sequential oxidation of 5-hydroxymethylfurfural to furan-2,5-dicarboxylic acid by an evolved aryl-alcohol oxidase. Biochim Biophys Acta 1868(1): 140293. https://doi.org/10.1016/j.bbapap.2019.140293

Vinambres M, Espada M, Martinez AT, Serrano A (2020) Screening and evaluation of new hydroxymethylfurfural oxidases for furandicarboxylic acid production. Appl Environ Microbiol 86(16). https://doi.org/10.1128/AEM.00842-20

Wang S, Bao L, Song D, Wang J, Cao X (2019) Heterocyclic lactam derivatives containing piperonyl moiety as potential antifungal agents. Bioorg Med Chem Lett 29:126661. https://doi.org/10. 1016/j.bmcl.2019.126661

Wesenberg D, Kyriakides I, Agathos SN (2003) White-rot fungi and their enzymes for the treatment of industrial dye effluents. Biotechnol Adv 22(1-2):161-187. https://doi.org/10.1016/j.biotechadv.2003. 08.011

Wongnate T, Chaiyen P (2013) The substrate oxidation mechanism of pyranose 2-oxidase and other related enzymes in the glucosemethanol-choline superfamily. FEBS J 280(13):3009-3027. https://doi.org/10.1111/febs. 12280

Heuts DPHM, Scrutton NS, McIntire WS, Fraaije MW (2009) What's in a covalent bond? On the role and formation of covalently bound flavin cofactors. FEBS J 276(13):3405-3427. https://doi.org/10. 1111/j.1742-4658.2009.07053.x

Regalado C, García-Almendárez BE, Duarte-Vázquez MA (2004) Biotechnological applications of peroxidases. Phytochem Rev 3(1):243-256. https://doi.org/10.1023/B:PHYT.0000047797. 81958.69

Publisher's note Springer Nature remains neutral with regard to jurisdictional claims in published maps and institutional affiliations. 